\title{
ARQUITECTURA MONUMENTAL Y ARQUITECTURA DOMÉSTICA EN LA CONTESTANIA*
}

\author{
FELICIANA SALA SELLÉS \\ LORENZO ABAD CASAL \\ Área de Arqueología \\ Universidad de Alicante
}

\begin{abstract}
Resumen. En este trabajo se toma en consideración un conjunto de edificios cuyas dimensiones, distribución interna y características constructivas permiten su calificación como residencias privilegiadas, con una posible función palacial. A su condición doméstico se añade la de representación social en el marco de la trama urbana ibérica, de manera que se podría ver en ellos los ejemplos contestanos de una arquitectura monumental doméstica. Finalmente, dicho análisis nos conduce a una serie de consideraciones sociales y políticas que explican la aparición de estos edificios en el Sureste peninsular a fines del s. VI a.C.

Palabras clave. Casas, palacios, Contestania, sociedad ibérica
\end{abstract}

\begin{abstract}
In this paper we consider a group of buildings whose dimensions, internal distribution and constructive characteristics allow their qualification as privileged residences, with a possible palatial function. Their domestic character is joined by that of social representation in the framework of the Iberian urban layout, so we could find the Contestan examples of a monumental domestic architecture. Finally, this analysis leads us to several social and political considerations that explain the appearance of these buildings in the south-east of the Iberian Peninsula at the end of the VI Century BC

Key words. Houses, palaces, Contestania, iberian society
\end{abstract}

Enunciado de esta manera, el título puede parecer pretencioso, puesto que en el campo de la arquitectura el calificativo de "monumental" se aplica a construcciones de grandes dimensiones, realizadas con técnicas constructivas cuidadas y elementos arquitectónicos destacados, características que muy pocas veces se cumplen en la Contestania ibérica. Sin embargo, los diccionarios al uso ofrecen acepciones de la palabra "monumento" que encajan mejor con la idea que de ella se tiene en el ámbito de la arqueología, independiente de su carácter 'monumental', bien porque se le atribuye un valor artístico, histórico y arqueológico, bien porque se le reconoce la condición de documento, de fuente de información histórica (RAE, Moliner y Casares). Lo "monumental" incluye también un matiz de representación social, pues no en vano

\footnotetext{
* Este trabajo se ha realizado en el marco del proyecto de investigación HUM 2006-09874: Romanización comparada: los casos de llici e llunum, del MEC.
}

la palabra monumentum deriva del verbo latino monere (avisar); un monumento sería cualquier construcción arquitectónica o escultórica erigida para conmemorar algo o destacar un lugar (Moliner), acepción que encaja mejor con el título que hemos elegido. Y si a esta identificación de "monumental" como algo muy grande o muy impresionante (Moliner) unimos la definición de "monumento" del Diccionari de l'art i dels oficis de la construcció de Fullana (1984), que se refiere a un edificio notable, como obra de arte o por su contenido histórico, entonces podremos hablar de la arquitectura monumental de carácter doméstico de la Contestania.

No obstante, en el territorio contestano sí existen algunos ejemplos de arquitectura monumental que cumplen los requisitos de estar construidos mediante técnicas cuidadas y elementos arquitectónicos decorados. Nos referimos a la arquitectura monumental funeraria que en la Contestania se materializó en dos modelos: el pilar-estela y el monumento turriforme. No nos vamos a detener en ellos, porque son hitos de 


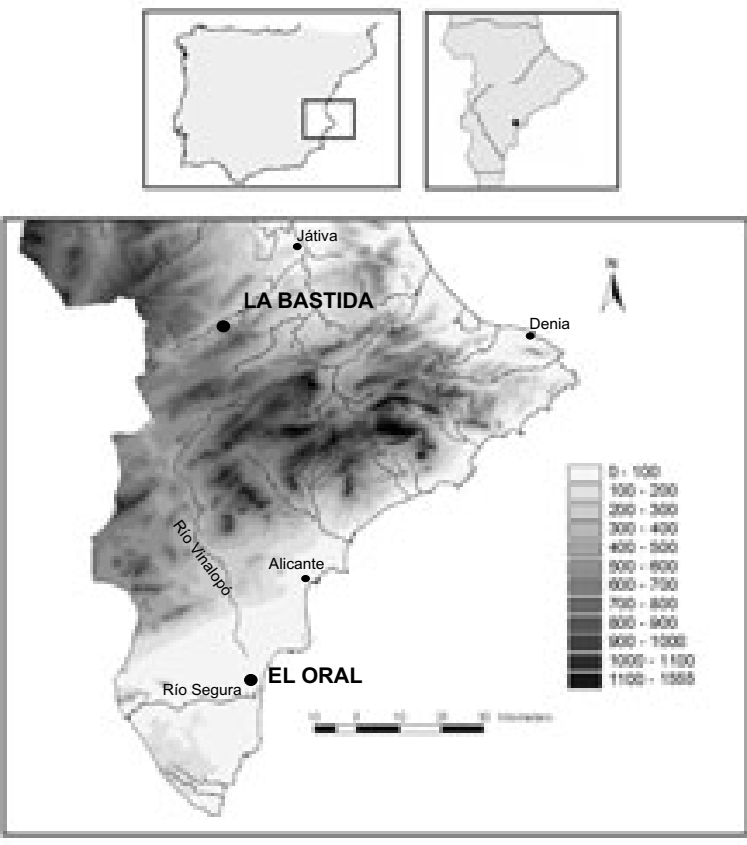

Figura 1: Mapa de la Contestania con la ubicación de El Oral y La Bastida.

la arqueología ibérica sobradamente conocidos (Castelo Ruano, 1995). No obstante, sí queremos recordar, por la novedad que representan para la investigación, el pilar-estela de la necrópolis del Molar, recuperado gracias a una reciente revisión de las excavaciones de Senent (Peña Ligero, 2003), y el monumento de Lo Mejorado, del que se ha publicado una propuesta de reconstrucción que no contempla el correspondiente estudio arqueológico e histórico (Varela Botella, 2000, 301-307).

Las dificultades para hablar de una arquitectura monumental contestana se acrecientan en el campo de la arquitectura religiosa, pues es aquí, y de forma más clara si lo comparamos con los patrones constructivos de otras culturas mediterráneas contemporáneas, cuando salta a la vista la inexistencia, quizá deliberada, de monumentalidad constructiva entre los iberos ${ }^{1}$. Los templos o los edificios con carácter cultual reconocidos en la Contestania, como los templos de la Illeta dels Banyets (Llobregat, 1985; 1988), el edificio de La Escuera (Nordström, 1967; Abad y Sala, 1997, 96 ss.) o el templo de l'Alcúdia d’Elx (Ramos, 1995), participan del rasgo más generalizado en la arquitectura ibérica: se trata de unas construcciones de materiales pobres,

1. Véase el planteamiento que realiza M. Belén $(2001,1)$ sobre el mismo problema en la arquitectura religiosa orientalizante. que utilizan madera y tierra para las cubiertas, tierra para los alzados y mampostería para los zócalos. Sólo las plantas de estos edificios, inusuales para una función doméstica, o la presencia de algunos elementos arquitectónicos que presuponen un espacio religioso dentro de la tradición milenaria mediterránea y proximooriental, como las columnas que flanquean simbólicamente el acceso ${ }^{2}$ o que se utilizan como elemento tectónico ${ }^{3}$, sirven para reconocer la singularidad funcional de la construcción, pero no acaban de conferirle un rango de monumentalidad.

Por último, si aplicamos la acepción del término monumental que hace referencia a edificios notables o de grandes dimensiones, podemos admitir la existencia en la Contestania de una arquitectura monumental de carácter doméstico. Se trata de una arquitectura sin fábricas destacables o cuidadas pero con excelentes acondicionamientos de los espacios interiores; edificios grandes, con un elevado número de estancias a las que el mero contraste con las construcciones domésticas básicas, de una o dos habitaciones, confieren un alto contenido de representación social. De acuerdo con este concepto, las viviendas que aquí destacamos son construcciones urbanas, de plantas complejas y tipología variada aunque con un elemento estructural común: la distribución interna organizada en torno a un patio ${ }^{4}$. Se corresponden, en definitiva, con construcciones domésticas privilegiadas dentro del conjunto urbano. Por el momento, en la región contestana sólo conocemos los ejemplos de La Bastida, de la primera mitad del s. IV aC, y de El Oral, un siglo más antiguos (Figura 1).

2. Queda demostrado en el caso del las columnas del vestíbulo del templo A de Campello. No ocurre igual en el templo de l'Alcúdia d'Elx, reconstruido con sendas columnas en las jambas de la puerta principal, ya que se desconoce la ubicación prístina del capitel eolio, que apareció reutilizado en un tabique de la basílica paleocristiana (Ramos, 1995, 12, 145). Podría tratarse también del remate de una única columna no estructural, a la manera de Torreparedones y de otros muchos ejemplos en el mundo oriental.

3. Según descubren las recientes revisiones de la arquitectura ibérica de la Illeta dels Banyets, los fustes de columna del altar del templo B estarían funcionando como verdaderas columnas de soporte de la cubierta.

4. La reciente documentación de este tipo de vivienda explica que no se vea recogida en la tipología de casas de C. Belarte (1996). 


\section{CASAS DESTACADAS DESDE EL PUNTO DE VISTA CONSTRUCTIVO}

De la Bastida tomamos en consideración una serie de departamentos excavados de forma independiente durante las primeras campañas de excavación, y después restituidos en una sola vivienda tras los trabajos de restauración dirigidos por $\mathrm{H}$. Bonet. Nos referimos, en concreto, a las casas 6 y 7 (Díes et alii, 1997, 235, fig. 9), de 110 y $120 \mathrm{~m}^{2}$ respectivamente, superficies que destacan sobre el tamaño medio de las casas de este poblado (Figura 2a). Otro dato que las caracteriza es el acceso desde un patio antepuesto. No obstante, la que más se aproxima a nuestra argumentación es la casa 10 (Figura $2 \mathrm{~b})$, recientemente revisada e interpretada como un edificio con posible función palacial (Díes y Álvarez, 1998), pues posee diversos rasgos que, en opinión de los investigadores, así lo acreditarían: una superficie mayor que la del resto de las casas, una ubicación privilegiada, la posesión de la única cisterna existente en el poblado y el hallazgo en su interior de materiales destacables, como el bronce del Guerrer de Moixent.

A nuestro juicio, como analizamos seguidamente, existe una diferencia sustancial entre los patios de estas casas y los patios de las casas de El Oral. La diferencia reside en el carácter orgánico del patio en la estructura de éstas últimas, rasgo que, desde el punto de vista constructivo al menos, nos remite a la tradición oriental y mediterránea de casas de múltiples estancias organizadas en torno a un espacio descubierto. En cambio, los patios de las casas de La Bastida poseen un carácter más sencillo, pues en casi todos los casos corresponden a espacios abiertos, posteriormente cerrados con una valla y englobados de este modo en la vivienda. La excepción de la casa 6 confirma esta norma, ya que el muro que cierra y forma el patio, aunque construido originalmente, en realidad configura un espacio abierto comparable al pórtico del modelo más antiguo de la casa a pastàs (Fusaro, 1982, 10, fig. 11-12).

En El Oral, las casas a las que aludimos se encuentran todas adosadas al lienzo oriental de la muralla, y tienen su entrada desde la calle longitudinal que corre paralela al mencionado tramo de muralla (Figura 3). Esta común y tan particular ubicación debe guardar alguna relación con la distribución social y funcional del tejido urbano, que empezamos a entrever. Otro rasgo que las define es el excelente acondicionamiento interno de sus estancias, para lo que emplean elementos constructivos sencillos pero muy efectivos, lo que confirmaría el elevado conocimiento por parte de los constructores iberos de las propiedades de los materiales de construcción y de las fábricas. Nos referimos a desagües de los patios mediante pequeños canales que atraviesan la muralla; empedrados de guijarros y pavimentos de adobe, a modo de rudus de la pavimentación, como aislantes de la humedad; pavimentos de arcilla saneados con enlucidos de una disolución de ceniza, un excelente hidrófugo; buenos enlucidos interiores con pintura mural; diversidad morfológica de los hogares que hacen pensar en una especialización funcional, bien para la cocción de alimentos, bien para caldear los ambientes de reposo; mesas de adobe de elaboración compleja, en torno a las cuales tienen lugar las reuniones del grupo, etc. Aunque no son elementos constructivos desconocidos, y muchos se documentan en el equipamiento de la arquitectura doméstica ibérica del área catalana (Belarte, 1997, 110-115), lo novedoso es verlos recogidos en una misma edificación ${ }^{5}$.

E. Díes y N. Álvarez $(1998,337)$, en su análisis de la función palacial de la casa 10 de La Bastida, y ante la ausencia de un discurso teórico de aplicación concreta al mundo ibero, proponen tres puntos de partida que parecen coherentes con la idea del papel de representación social en ciertas construcciones ibéricas. El primero es, por supuesto, el tamaño del edificio en relación con los restantes; el segundo, la categoría del ajuar hallado en su interior; el tercero y último, la calidad de los acabados de la construcción, que los mencionados investigadores resumen en el uso de la cal y la decoración pictórica. Respecto a este tercer punto, se comprende que, al partir de un registro deficitario, consecuencia de la metodología al uso en los años de las primeras excavaciones en La Bastida, los mencionados autores destaquen únicamente estos dos elementos que, en efecto, tienen una relevancia per $\mathrm{se}^{6}$. Sin embargo, el registro de las excavaciones recientes en El Oral descubre, claramente en nuestra opinión, que no sólo el material constructivo foráneo -la cal- o de ornato -la deco-

\footnotetext{
5. Estos elementos tienen su precedente en la arquitectura doméstica de La Rábita de Guardamar desde la primera mitad del s. VII a.C.

6. Mantenemos nuestras reservas sobre la identificación automática como cal de los enlucidos interiores de coloración blanquecina sin un análisis físico-químico, al menos en las casa ibéricas del sureste peninsular. Los últimos hallazgos en El Oral señalan que muchos enlucidos son de yeso. Véase Abad et alii, 2001, 118-119.
} 


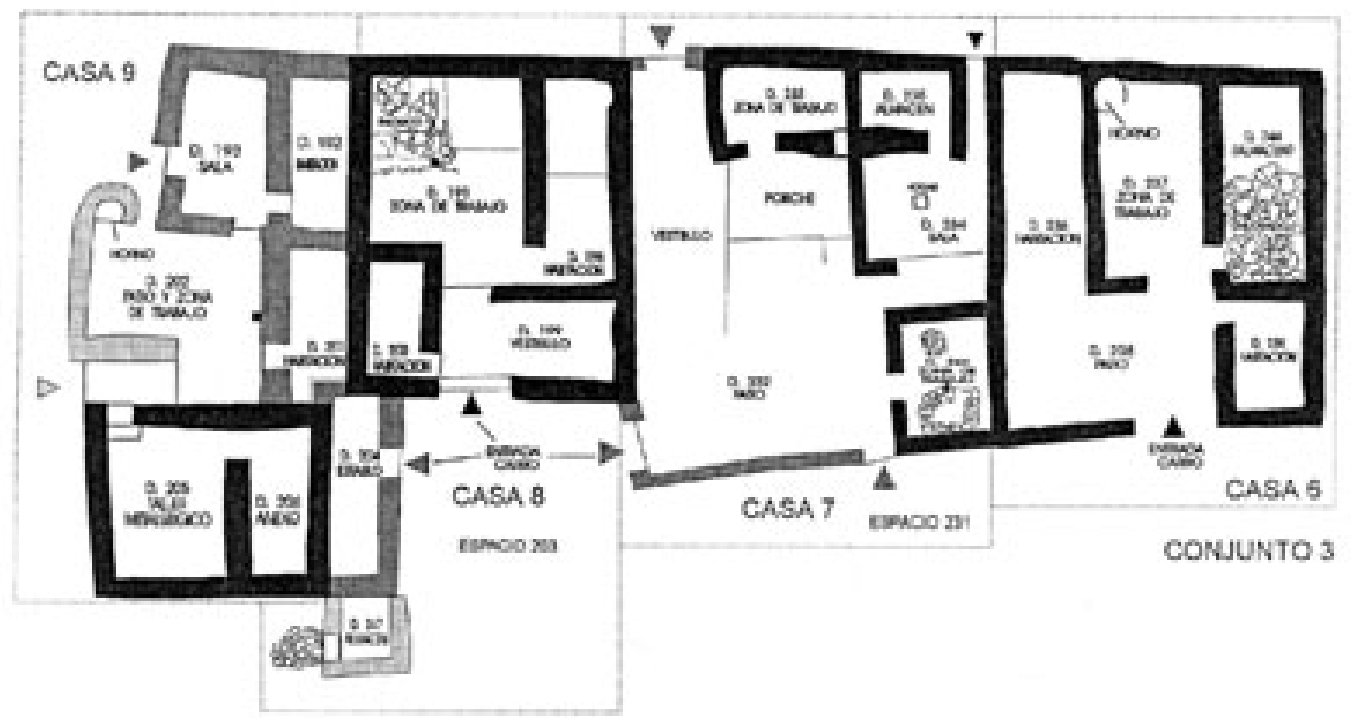

$\stackrel{N}{N}$

\begin{tabular}{|c|c|}
\hline 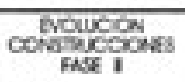 & Snevicas \\
\hline $\begin{array}{l}\mathbf{E}_{1 \mathrm{~A}} \\
\mathbf{E}_{1 \mathrm{~B}}\end{array}$ & $\begin{array}{l}4 \text { Entrabs } \\
\text { - Haper }\end{array}$ \\
\hline$\square_{n c}$ & (1) Marn \\
\hline
\end{tabular}
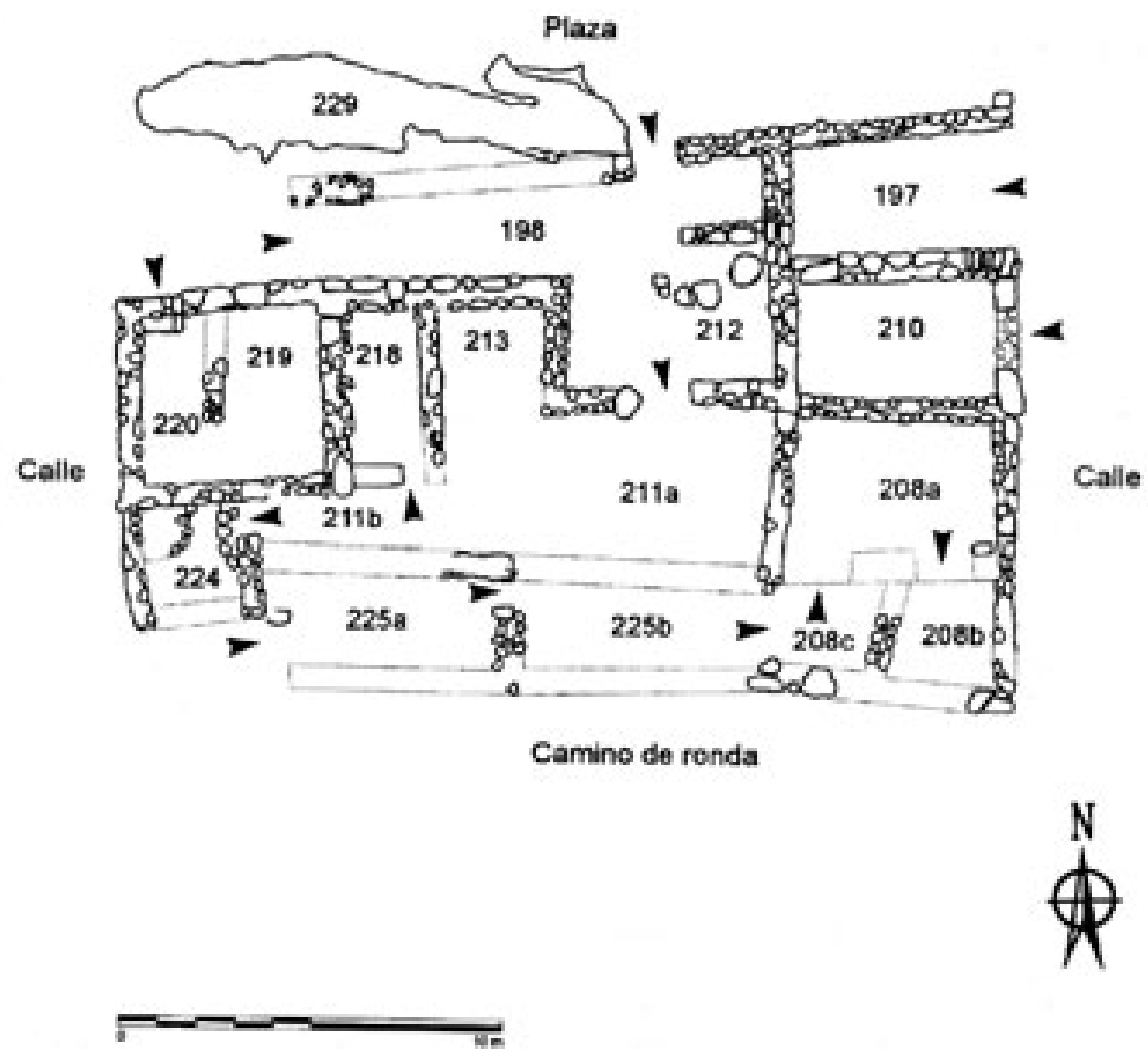

Figura 2: Casas con patio de La Bastida: a. Casas 6 y 7; b. Casa 10 (elaboración propia a partir de Díes et alii, 1998; Díes y Álvarez, 1997) 


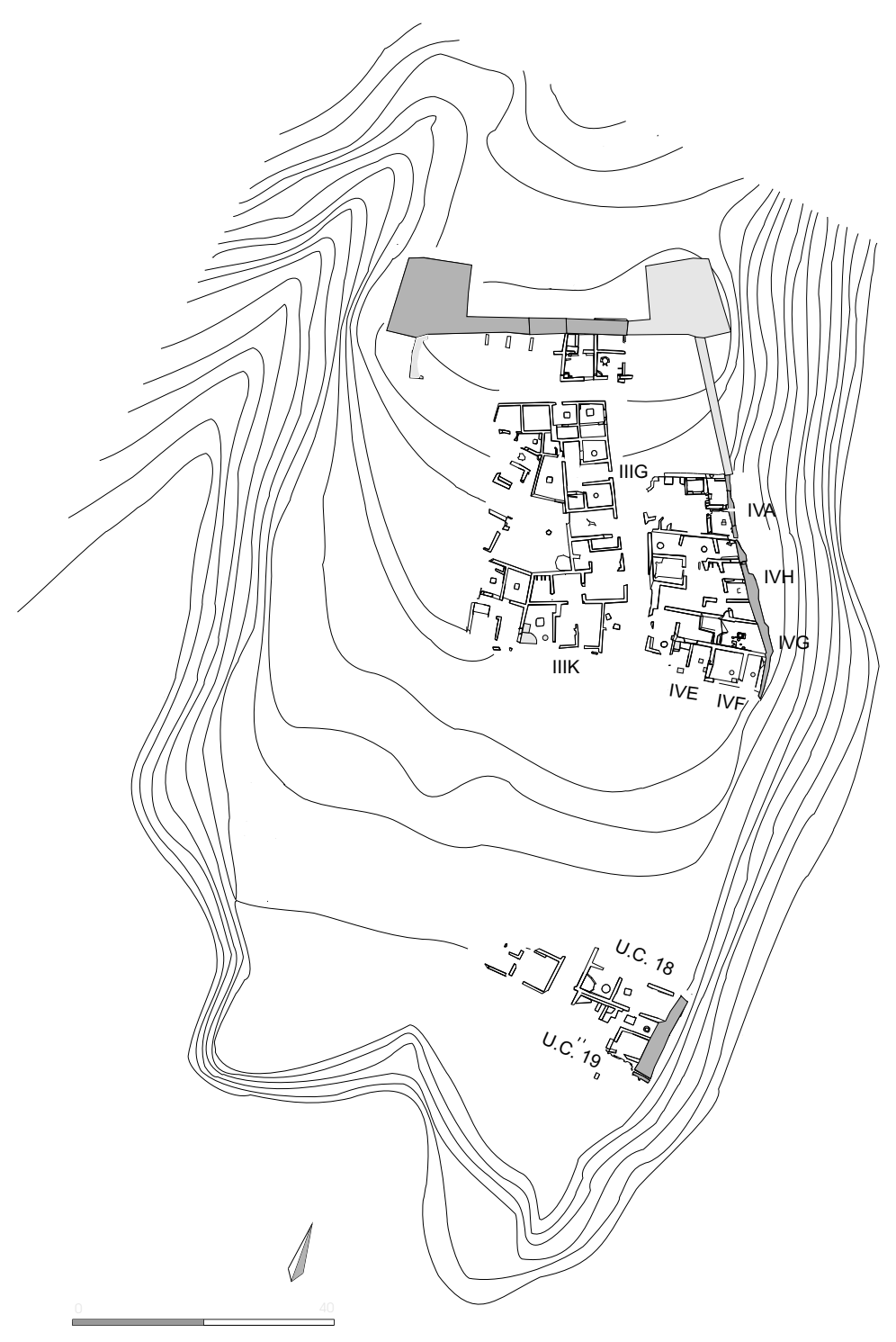

Figura 3: Planimetría general de El Oral.

ración mural-7 poseen la capacidad de destacar una construcción, sino también todas aquellas disposiciones que mejoran la habitabilidad y que no son comunes a la mayoría de las viviendas de un poblado, o que aparecen reunidas en una vivienda, como ocurre en la casa IVH.

En cuanto al segundo punto, la presencia de un ajuar doméstico rico o destacado, no siempre puede valorarse de forma satisfactoria. No sería necesario advertir al lector, por ser una experiencia generalizada, que los objetos muebles

7. La pintura mural, sobre todo si está aplicada en el tercio inferior de la pared, puede tener también una finalidad higiénica, y así ocurre actualmente en viviendas de barro del Atlas marroquí (Mimó, 1996, 67). son, parafraseando a M. Bendala ${ }^{8}$, trasladables o movibles, y su valor indicativo, que puede ser muy alto, puede verse alterado en virtud de la propia movilidad, y, en consecuencia, su hallazgo en un contexto concreto puede no siempre conservar la función y el significado prístinos. Hay que admitir, por otro lado, que el valor que nosotros otorgamos en la actualidad a los objetos arqueológicos puede no coincidir con el que realmente tuvo en el momento de uso, por la facilidad de incorporación o aceptación, en determinados casos, fuera de su ámbito propio, o de su mutabilidad por razones que pueden ser trascen-

8. Presentación de la obra Arquitectura oriental y orientalizante en la Península Ibérica, editada por D. Ruiz y S. Celestino en 2001. 


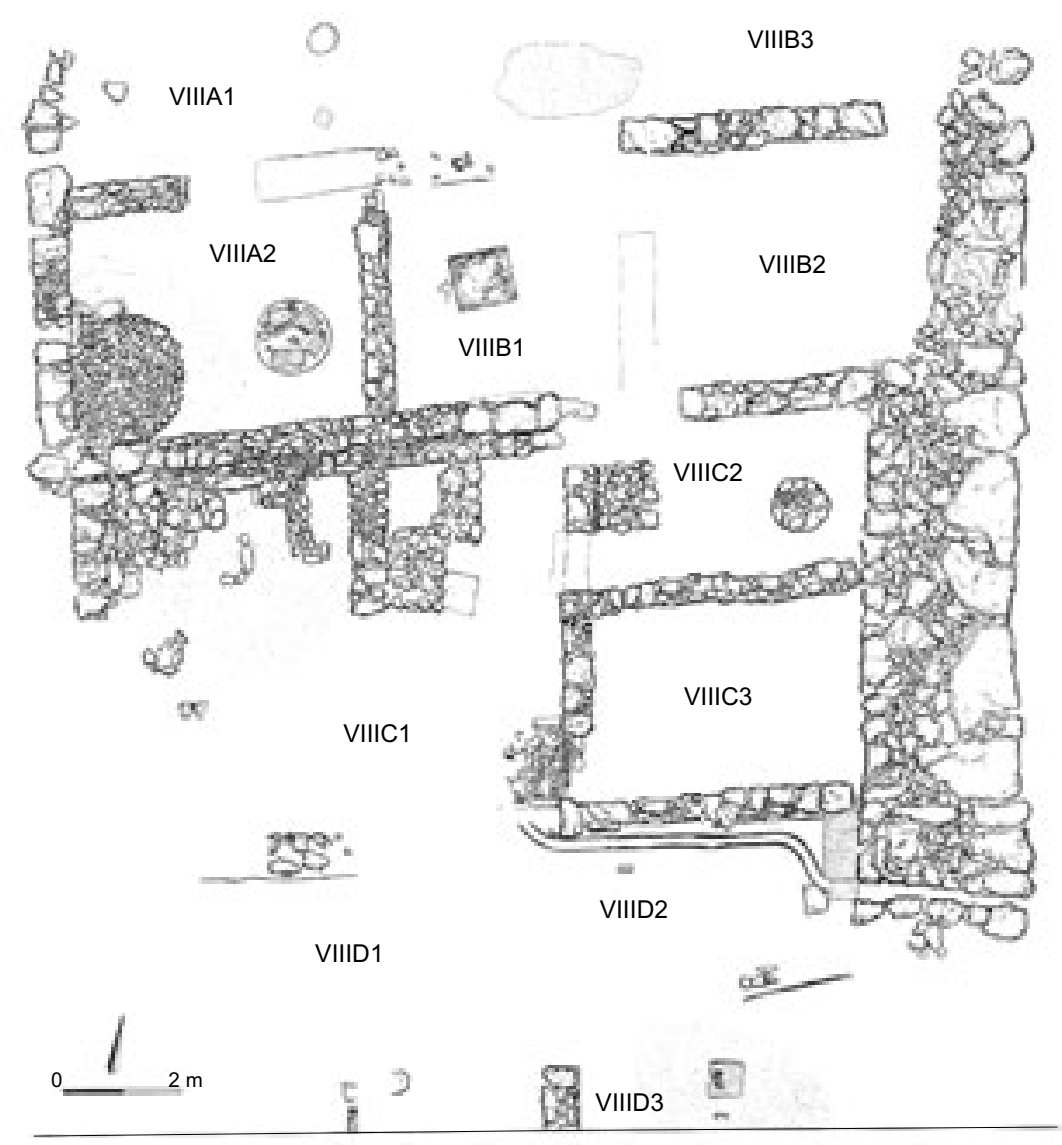

Figura 4: Unidades constructivas 19 y 18 de El Oral.

dentes o simplemente anecdóticas. Además, las circunstancias del final de la ocupación del hábitat o los procesos post-deposicionales pueden alterar asimismo el contexto material. Conscientes de estas limitaciones, ante un análisis como el que nos ocupa no podemos sino decantarnos y enfatizar los aspectos arquitectónicos como elementos de juicio más fiables, es decir, los materiales y técnicas constructivas, de un lado, y el tamaño de los edificios, de otro. El conjunto mueble podrá corroborar o matizar la interpretación obtenida, pero nunca será determinante.

En este punto, salta a la vista la conveniencia de tipificar la arquitectura ibérica, una labor que debe ser la consecuencia final de los trabajos de análisis y síntesis regionales publicados en la década pasada ${ }^{9}$. Sistematizar y dar contenido al concepto de "cultura arquitectónica" defendido por M. Bendala, aplicado en este caso al mundo ibérico, nos ayudaría a valorar los

9. Por su trascendencia en la investigación, citaremos como ejemplos los estudios de C. Belarte (1997) para el área catalana y de C.-A. de Chazelles (1997) para el sur de Francia. elementos arquitectónicos heredados de la tradición constructiva y los que aparecen por impulsos externos. Nuestra experiencia en El Oral es una muestra de la necesidad de esa tipificación, ya que las primeras de estas construcciones con patio, adosadas a la muralla oriental en el sector VIII (Abad y Sala, 1993, 132-137, fig. 147) no pudieron ser valoradas como tales por falta de elementos de referencia. Sólo cuando se terminó de excavar la casa IVH, en la campaña de 1998, pudimos reconsiderar la cuestión.

\subsection{Unidad constructiva 19}

La revisión de la documentación arqueológica ha permitido reinterpretar el edificio y proponer su organización en torno a un patio (VIIIC1), en cuyos lados este y sur se abrirían las diversas dependencias: cuatro habitaciones, tal vez cinco (VIIIC2, VIIIC3, VIIID1, VIID2 y VIIID3) (Figuras 3 y 4). El dato clave ha sido la presencia de un canal de desagüe, en este caso decorado con conchas, que, como en los restantes ejemplos, recoge el agua del área abierta (VIIIC1) para ver- 
terla a extramuros cruzando una de las estancias adosadas a la muralla (VIIID2).

El patio, VIIIC1, es además el espacio donde se concentran la mayoría de las actividades diarias, artesanales o domésticas. Estas se llevarían a cabo utilizando las estructuras adosadas a la pared norte, lo que obliga a creer que al menos todo este sector estaría techado con una cubierta ligera y abierto totalmente al resto del patio. Desconocemos de qué tipo de labores se trata, pues el registro de las estructuras ofrece pocos datos significativos. Por su parte, las estructuras de VIIIC2, un banco circular y otro cuadrado de mampostería, revestidos de barro, también indican un área de trabajo doméstico.

VIIIC3 parece ser la dependencia más destacada, a juzgar por el cuidadoso mosaico de conchas que construyen como umbral. No se ha profundizado lo suficiente en este detalle tan particular de los umbrales de conchas en El Oral, que hasta ahora no se han documentado en casas ibéricas. Los pocos paralelos conocidos se encuentran en el escalón de entrada a una vivienda del barrio fenicio del s. VIII a.C. del Castillo de Doña Blanca (López Amador et alii, 1995), o en el umbral de una estancia del Poblado Bajo del Carambolo (Carriazo, 1973, 283, lám. 193194, 206), recientemente reinterpretado como un santuario fenicio (Belén y Escacena, 1995, 86; Belén Deamós, 2001, 6-7) ${ }^{10}$. Aparte del umbral, una gruesa capa de piedras y tierra bajo el pavimento eleva el nivel del suelo y contribuye a drenar la humedad subyacente, detalle que también indica el carácter principal de esta estancia: un lugar de representación, de reunión o sencillamente de reposo. Las restantes habitaciones, bastante peor conservadas, no se pueden interpretar. En todo caso, VIIID3 podría tratarse de un espacio de cocina por la presencia de un hogar sencillo de placa.

\subsection{Unidad constructiva 18}

Inmediatamente contigua al norte, tenemos la unidad constructiva 18. Aquí, las estancias VIIIA1 y VIIIB3, que no aparecen diferenciadas por ninguna pared intermedia y presentan además la misma pavimentación, una simple capa de tierra blanquecino-amarillenta, constituyen muy probablemente el patio al que abren el resto

10. En el sur de Francia, C.-A. de Chazelles (1996, 295-296, 304) recoge algunos ejemplos más tardíos de Lattes. de las estancias. De éstas, sólo conocemos las tres meridionales (Figuras 3 y 4 ).

En VIIIA2, de nuevo encontramos el binomio formado por una estructura cuadrangular adosada a la esquina y otra circular de menor diámetro. La primera, provista de sendas capas refractarias de piedra menuda y fragmentos de cerámica, y una última y superior de arcilla muy alterada por el fuego, confirma su carácter de basamento de horno dedicado a la cocción de alimentos; en cambio, la pequeña estructura circular, sin huella alguna de fuego, debió servir como banco de trabajo auxiliar para las tareas en el horno. VIIIB1 y VIIIB2 están comunicadas entre sí reproduciendo el esquema doméstico básico de estancia primera con hogar, área de cocina pero también de reposo, y estancia más reducida al fondo, probablemente área de almacén y/o reposo.

\subsection{La casa IVH}

Es una de las viviendas mayores del poblado, con unos $209 \mathrm{~m}^{2}$, y es poseedora, además, de una distribución interna bastante particular que ha sido determinante para plantearnos el significado social de estas casas.

El aspecto que ofrece es el resultado de unas reformas que transformaron la distribución original. En un primer momento (Figura 5, 1), la vivienda estaría constituida por las cuatro estancias cuadradas adosadas a la muralla y, en el lado opuesto, en una posición centrada, una sola habitación mayor que las anteriores. El espacio intermedio debió estar descubierto en su parte central. Así lo dan a entender, por un lado, su amplia crujía y, por otro, la existencia de un pequeño canal que arranca desde un lateral, cruza IVH4 adosado al muro septentrional y desagua a través de la muralla.

A la segunda fase (Figura 5, 2) corresponde la construcción del tabique en el extremo noroccidental del patio, cerrando un espacio antes completamente abierto pero techado, la habitación IVH7. Se construye otro tabique en L en el ángulo suroriental que delimita una nueva habitación, IVH1. Por último, es también ahora cuando se construye el banco de conchas frente a la puerta de IVH8, cuya existencia obliga a prolongar hacia el sur la zona techada. La estructura en cuestión consiste en un muro de mampuesto en forma de $\mathrm{L}$ que se adosa y arranca desde la pared divisoria de IVH4 y IVH5. Por la parte exterior del extremo corto de la $L$ se adosa a su vez un banco rectangular de barro decorado con 


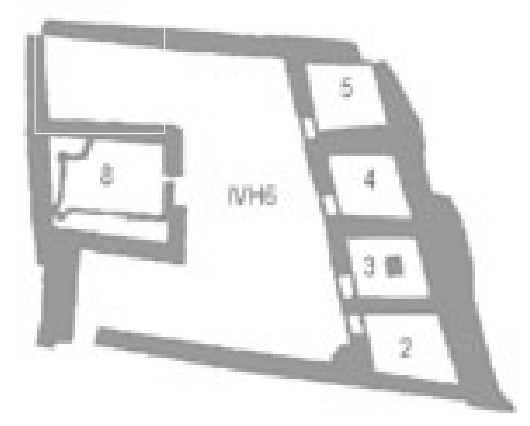

1

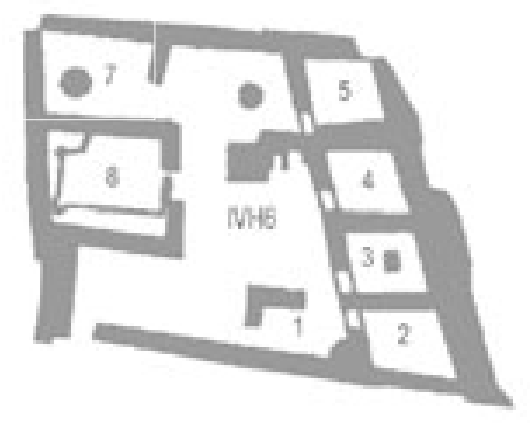

2

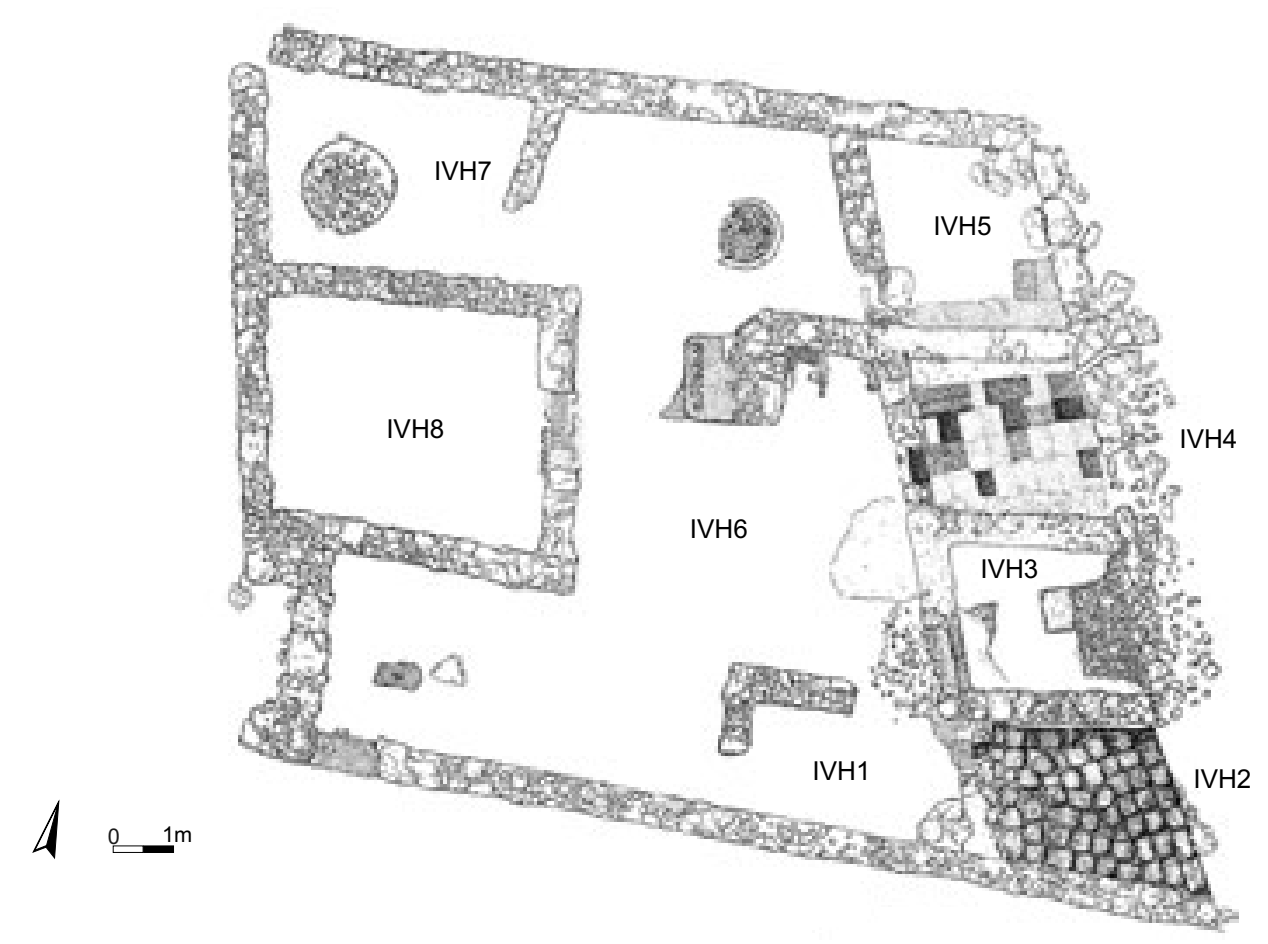

Figura 5: Casa IVH de El Oral: fases constructivas y plano general.

una cenefa de conchas en su parte superior; en el interior de la $\mathrm{L}$, adosados al tramo largo, tres adobes dispuestos a perpiaño y casi en paralelo señalan otro elemento más de esta estructura, quizá un soporte para un banco de madera. Pero, probablemente, el mayor interés de esta construcción resida en la decoración parietal de conchas detectada todavía adherida a los adobes caídos en el espacio interior de la $L$, para la que no conocemos paralelos.
En las dos fases, la entrada a la casa se efectúa desde un sencillo vano de unos $90 \mathrm{~cm}$ de ancho, abierto en el extremo del muro maestro meridional (Figura 5, 2). Esta entrada conduce al patio central a través de un vestíbulo alargado. De esta manera, para acceder a los ámbitos más privados de la casa hay que utilizar una entrada de codo, muy frecuente, por otro lado, en casas de tipo pastàs (Fusaro, 1982, 13). IVH6 es, por tanto, el patio descubierto que articula la distribu- 
ción de la vivienda y tiene un claro carácter multifuncional, con un área techada pero abierta en el extremo septentrional dedicada expresamente a la cocina. En sus lados este y oeste, las habitaciones de servicio y las de reposo o reunión.

Los dispositivos y elementos constructivos que mejoran los espacios interiores de esta vivienda son los siguientes ${ }^{11}$. En IVH2, un pavimento de adobes infrapuesto al suelo de arcilla lo preserva de la humedad del suelo. Esta disposición de los adobes, que también se encuentra en habitaciones de reposo, indica aquí un espacio de almacén, interpretación que en este caso también vendría avalada por el hallazgo de diversos vasos cerámicos sobre el suelo. El recurso a enlosados de adobes como preparación del suelo cuenta con una cierta tradición en la arquitectura proximo-oriental (Aurenche, 1981, 163), donde lo encuentran aplicado tanto en estancias domésticas como en áreas artesanales o de almacén ${ }^{12}$.

En cambio, el cuidado puesto en el acabado final de la habitación contigua, IVH3, señala un área de reposo o de reunión: paredes pintadas, empedrado de guijarros aislante del suelo, una capa de arcilla verdosa como pavimento y una mesa central hecha con un adobe. A continuación, IVH4 es también un lugar de reposo y/o comedor, acondicionado con un pavimento de adobes infrapuesto, un suelo de finas capas alternantes de yeso y ceniza diluida y decoración pintada parietal. No obstante, el hallazgo de cuatro pesas de telar y una aguja de bronce permiten interpretar la estancia como un lugar de presencia y actividades femeninas. La decoración pintada de las paredes y un banco corrido otorgan un alto valor como área de reposo a la habitación siguiente IVH5, papel que muy posiblemente tuvo en la primera fase; sin embargo, puesto que esta función ya se cumple en otras estancias y dado que se encuentra en comunicación directa con el ámbito de la cocina, optamos por dar a esta habitación un uso como almacén. Por último, las dos estancias añadidas con la reforma se corresponden con un área de trabajo anexa a la cocina, IVH7, y a una zona de almacén, IVH1, complementaria de la ya existente en IVH2.

11. Para los detalles de su hallazgo remitimos a la memoria de excavación: Abad et alii, 2001, 65-83. Asimismo, los criterios para el análisis funcional aparecen razonados en el capítulo correspondiente de la mencionada memoria.

12. En la arqueología ibérica, el taller de lino de Coll del Moro de Gandesa (Tarragona) constituye un claro ejemplo de pavimentos de adobe en instalaciones artesanales relacionadas con el agua: véase Rafel et alii, 1994.
IVH8 fue en ambas fases la habitación noble de la casa por sus dimensiones, su posición central claramente destacada, su nivel de suelo algo sobreelevado con respecto al resto de la casa y su acondicionamiento interior, exactamente igual a IVH3: un empedrado de guijarros de calcarenita aislante de la humedad del suelo de arcilla encalado, como en IVH4. Durante su excavación no se pudo documentar pintura mural, aunque estamos convencidos de que la tuvo.

\subsection{La casa IVA}

Se trata de la más septentrional de las casas con patio descubiertas hasta ahora y vecina de $\mathrm{IVH}$, de la que contrasta por su menor tamaño. Es el único ejemplo en que el patio (IVA1) no tiene una ubicación central, sino que se antepone al resto de la casa, siendo el lugar por donde se accede a la vivienda a través de un amplio vano (Figura 6). Es asimismo el lugar donde se ubican las estructuras que implican algún tipo de actividad doméstica, todas ellas adosadas a las paredes norte y sur, de lo que deducimos que ambos laterales estarían techados con una cubierta ligera, a modo de pórtico. Además, el pavimento del patio se extiende desde la zona central hacia los laterales sin cambio ni ruptura alguna.

Suponemos que IVA1 debió ser también el área de preparación de alimentos porque ninguna de las estancias restantes presenta un ambiente claro de cocina. Sólo en IVA3 tenemos una superposición de dos hogares sencillos de placa asociados a sendos pavimentos que, de alguna manera, indican una actividad no interrumpida que, sin embargo, no produce los estratos con desechos orgánicos típicos de los ambientes de cocina; el ajuar hallado en la estancia --una urna de orejetas y una olla de cocina, ambas incompletas-- tampoco ayuda demasiado a identificar dicha actividad. La habitación es bastante pequeña y el espacio que queda libre entre el banco y los hogares resulta poco operativo, por lo que creemos que pocas actividades se pudieron desarrollar en su interior, salvo que se tratase de un lugar de reunión en el que también se comiese, aprovechando los hogares de placa para caldear la habitación o mantener la comida caliente. La estera colocada en su puerta y la buena calidad de la doble pavimentación parecen confirmar la idea de que estamos ante una estancia de reunión.

IVA2 es la otra estancia de esta casa provista de hogar cuyas características tampoco lo 


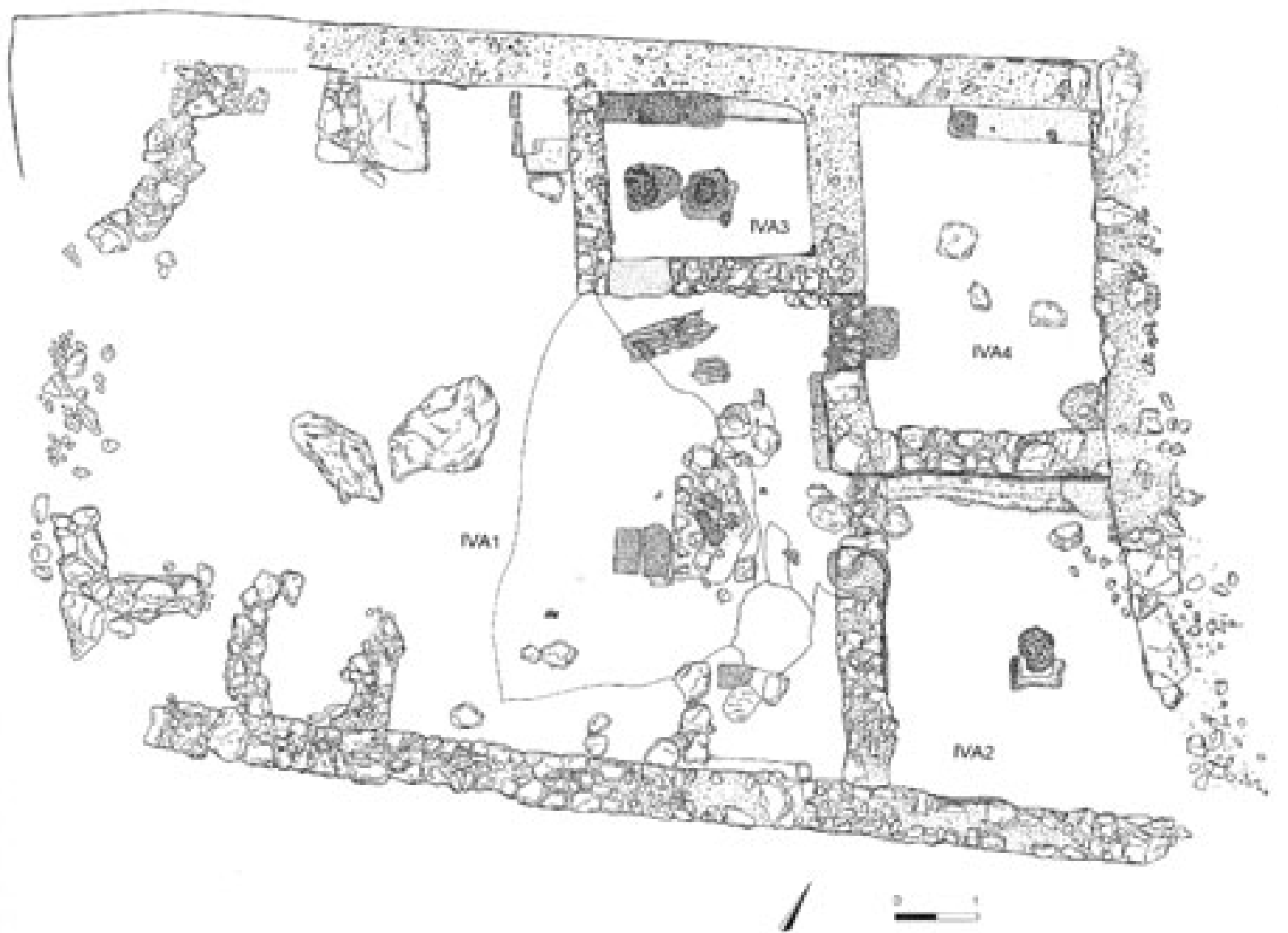

Figura 6: Casa IVA de El Oral.

hacen apto para la cocción. El espacio apareció con el pavimento completamente limpio, con la excepción de unos pocos fragmentos cerámicos residuales y diez pesas de un telar que estuvo apoyado en la pared zaguera frente a la puerta. El cuidado puesto en la pavimentación y en el enlucido de las paredes es indicativo de que se trataba de una estancia de reposo, probablemente el espacio de las mujeres. En su puerta se abre la atarjea del canal de desagüe del patio que discurre pegado a la pared norte, atraviesa la muralla y evacua al exterior.

IVA4 es la estancia de mayores dimensiones y sólo presenta un banco corrido adosado a la pared del fondo. Apareció sin apenas materiales -dos pesas de telar y algunos fragmentos residuales de cerámica-, con un buen pavimento de arcilla y un escalón de bajada en el umbral, todo lo cual apunta de nuevo hacia esos ambientes mixtos de reposo y de despensa.

\section{OTROS EJEMPLOS DE CASAS DESTACADAS}

En El Oral existen otras construcciones con una superficie destacable. En lo que respecta a su tamaño, creemos oportuno recordar aquí las casas IIIG y IIIK (Figura 7).

\subsection{La casa IIIG}

Es una de las más interesantes en cuanto al uso de los espacios, ya que las obras y reformas que se realizan, dirigidas a ampliar el espacio útil, parecen conservar las funciones domésticas y familiares para las que fue concebida. Como ya se ha dicho (Abad y Sala, 1993, 62), IIIG tiene en origen una forma rectangular y está constituida por una serie de estancias articuladas en torno a un vestíbulo en forma de $T$. En realidad, la casa 


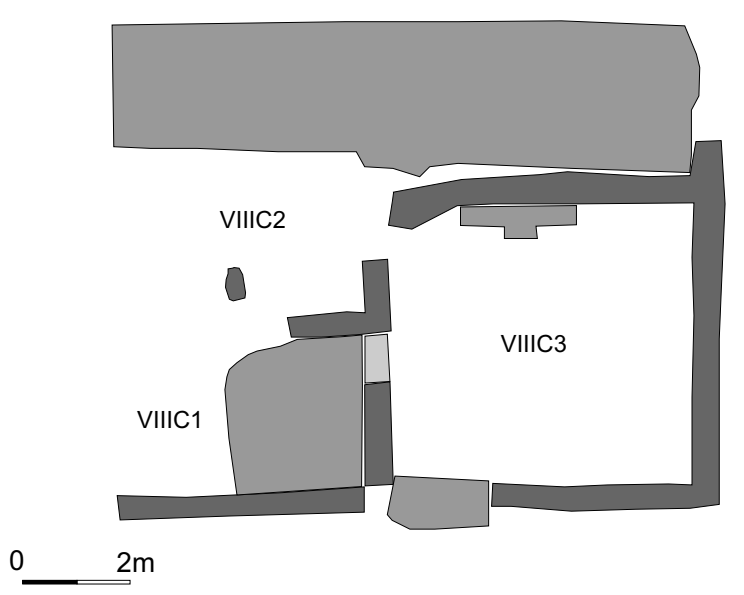

Casa VIIC

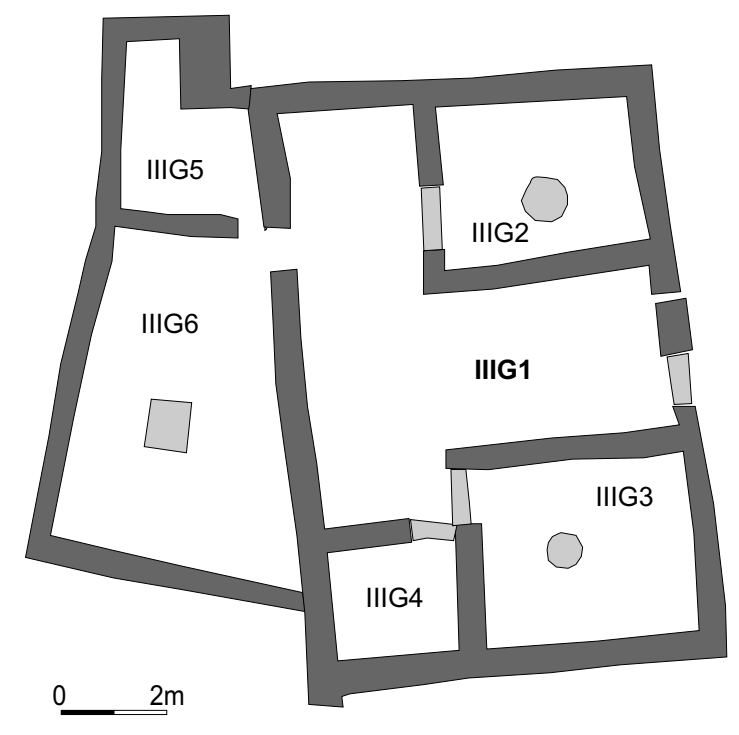

Casa IIIG

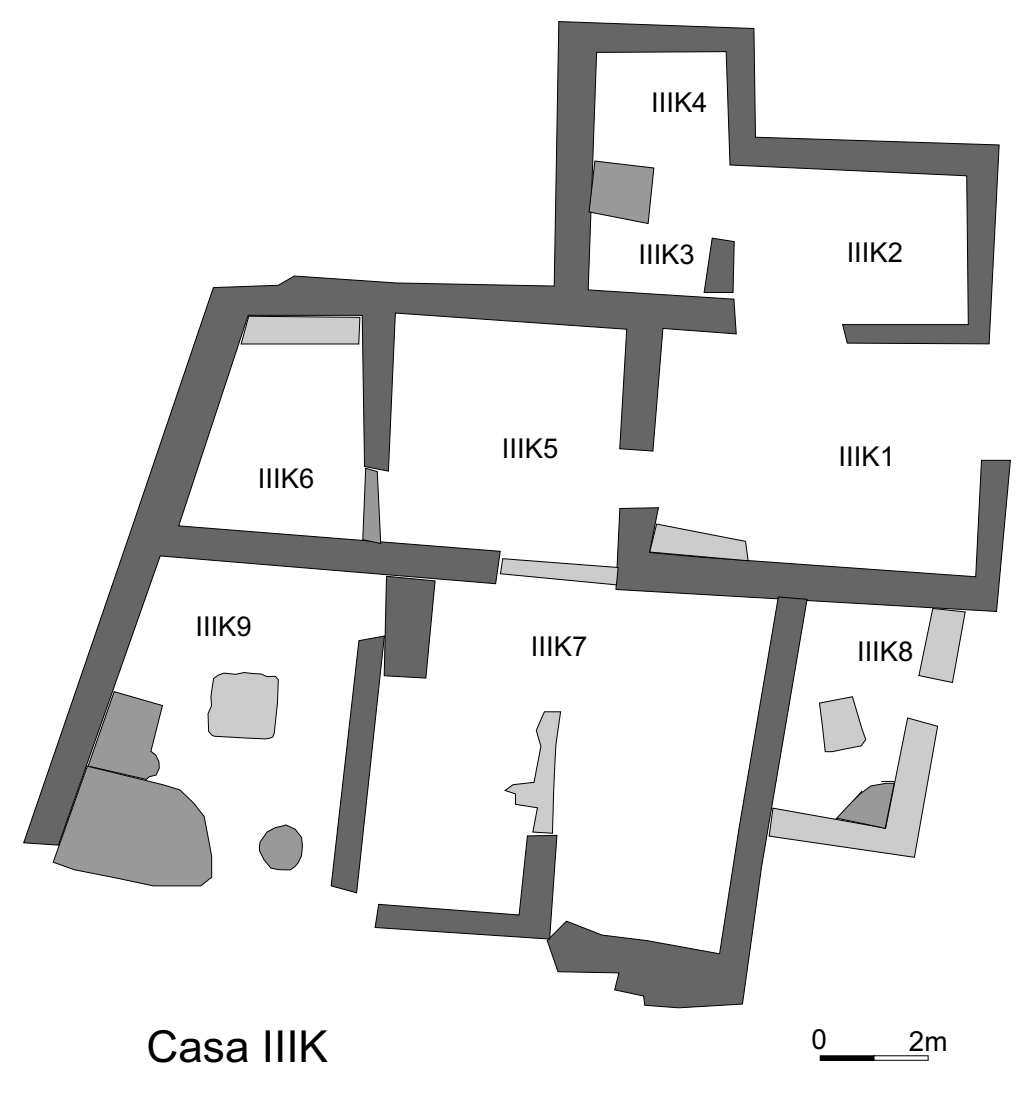

Figura 7: Casas VIIC, IIIG y IIIK de EI Oral.

repite de forma simétrica el esquema más senciIlo de vivienda conocido en El Oral: una estancia principal con hogar (cocina y reposo) más un espacio menor anexo de almacén. Con el tiempo, se añaden otras dos estancias con funciones idénticas, para lo cual, y este dato es de gran importancia, se toma espacio público de la plaza para integrarlo en el ámbito privado de la casa, lo que contribuye a que el plano de la vivienda adopte una forma irregular. 
El vestíbulo es el distribuidor de la circulación interna de la casa, y también un área de trabajo: el espacio donde se desarrollan las labores diarias, a juzgar por el registro arqueológico. Por necesidades de luz y de ventilación, debió estar abierto en el tramo más cercano a la calle y techado en el brazo horizontal de la T, dando así cobijo a las puertas de las estancias menores y a las actividades cotidianas en la casa. Este vestíbulo es, por tanto, un patio, si bien no tiene el carácter orgánico que otorgamos a los patios con desagüe de las casas adosadas a la muralla oriental. Sin embargo, al vestíbulo se accede desde la calle III-IV a través de un portalón de 2,10 m de ancho, por lo que se ha interpretado como una entrada para carro ${ }^{13}$, elemento cuya relevancia socioeconómica en la cultura ibérica contribuye a destacar esta vivienda. De hecho, antes de tener constancia de las casas con patio central, la casa IIIG pasaba por ser la más destacada del conjunto urbano conocido (Abad y Sala, 1993).

Si admitimos que IIIG sigue el esquema doméstico básico ya mencionado, aunque repetido tres veces, el análisis puede derivar hacia la identificación de la estructura del grupo familiar que habita en esta vivienda. Parece plausible que la incorporación de un tercer conjunto -estancia de cocina/reposo más estancia de almacén- a los dos iniciales responde al crecimiento del grupo familiar, probablemente para cubrir las necesidades con una nueva unidad doméstica. Es posible, por tanto, que los habitantes de esta casa se estructuren socialmente en tres grupos familiares reducidos vinculados por un lazo parental, o por una relación de tipo clan.

Pero, por otra parte, no podemos olvidar que la casa IIIG también admite una lectura de género a partir de la tipología de los hogares y del contexto material asociado. Así, en IIIG2 y IIIG5 tendríamos los verdaderos lugares para la preparación de los alimentos y para la comida, ya que cumplen requisitos esenciales como estar provistas de hogares complejos (capas refractarias) o poseer sendos cuchillos afalcatados, reflejo de manipulación y preparación de alimentos casi tanto como las ollas de cocina, y por supuesto, de la división y reparto de las raciones entre los comensales. En cambio, el hogar de IIIG3, una simple placa, podría servir para caldear el espacio, convirtiéndolo en un área de reposo. La presencia de un conjunto variado de platos

13. Al final será tapiado para dejar un vano de ancho normal de unos $90 \mathrm{~cm}$. y en especial de una fusayola podría indicar el espacio de reunión de las mujeres dedicado a actividades propias, por ejemplo, al hilado. En esta hipotética distribución funcional de la vivienda, IIIG5 y IIIG2 corresponderían a los lugares de cocción de los alimentos, la primera de ellas, y de comida y reposo de los hombres del grupo familiar, la segunda.

\subsection{La casa IIIK}

IIIK presenta una distribución interna difícil de parangonar con cualquiera de las construcciones domésticas del poblado, con detalles inusuales como que la única estancia equipada con hogar tenga una ubicación excéntrica, o que las restantes habitaciones, de dimensiones bastante similares entre sí, sean anormalmente amplias. Además, una serie de obras y reformas en la fachada sur la convierten en una de la unidades más complejas desde el punto de vista constructivo (Abad et alii, 2001, 32-33, fig. 83-84). Es, junto a IVH, una de las casas de mayor tamaño del poblado, pero no reúne los requisitos constructivos que destacamos en este trabajo: no posee patio central, por ejemplo, ni todas las estancias presentan buenos acondicionamientos internos. Sin embargo, presenta otros rasgos, no exentos de una lectura ciertamente relevante, que a continuación describimos.

En una primera fase, la casa IIIK tuvo su acceso principal desde el sur, a través de una gran puerta abierta a la plazoleta que forman la confluencia de las calles III-IV y III-V. IIIK5 constituye, por tanto, el vestíbulo propiamente dicho. A su vez, la estancia IIIK9, la única con hogar y equipamiento doméstico, también tuvo su entrada desde dicha plazoleta mediante una puerta independiente. Con el tiempo, posiblemente la necesidad de espacio conduce a unas reformas, consistentes en la construcción de unas habitaciones al este de IIIK9 ${ }^{14}$, las estancias IIIK7 y IIIK8, que van incorporando la plazoleta a la vivienda de manera progresiva. Así, pues, tenemos aquí un segundo caso en el poblado en el que el ámbito privado, en principio doméstico, invade espacio público.

IIIK6 es la única estancia con un acabado más cuidado en el pavimento y las paredes, y está equipada con un banco corrido de adobes.

14. Lo que obligó a tapiar la puerta de IIIK9 y a abrir otra al sur, en la pared hoy desaparecida que daba a la calle IIIV. Para la descripción de las fases constructivas véase Abad et alii, 2001, 32-33, fig. 84. 
Apareció vacía con la excepción de un brazo de balanza, cuyo tamaño y forma señalan que sirvió para pequeños pesos, muy presumiblemente de materiales costosos como el oro, la plata, esencias, etc. Por otra parte, IIIK9, donde se concentraron las actividades culinarias y domésticas cotidianas, fue también el ambiente de reunión y reposo de las mujeres, tal y como da a entender el hallazgo de un telar vertical apoyado en la pared oriental y de una lekanis.

IIIK6 y IIIK9 constituyen sendos ejemplos de las reservas que debemos mantener en la valoración de los objetos muebles, pues el brazo de balanza y un vaso griego de tocador, bastante escaso en la Península Ibérica, podrían hacer que valorásemos este edificio sobre los demás. Sin embargo, la arquitectura o la calidad de la construcción en las estancias no son acordes con este juicio. En la casa IIIL, vecina a IIIK, se podría aplicar la misma observación respecto a la discordancia entre ajuar y arquitectura en una valoración social. La casa IIIL, como IIIK, no destaca en cuanto a las técnicas y elementos constructivos pero, paradójicamente, forman parte de su ajuar un importante conjunto de objetos de bronce -olpe etrusco, rallador y asador-, huevo de avestruz y de ánade decorados y vasos áticos, que son los objetos hasta ahora de mayor riqueza objetiva encontrados en el poblado ${ }^{15}$.

\subsection{La casa VIIC}

Aunque está excavada parcialmente (Abad y Sala, 1993, 117-121, fig. 164), nos interesa traer a colación la casa VIIC a causa de algunos particulares constructivos que también presenta (Figura 7). Aparece asociada a un pavimento de guijarros, descubierto en un tramo de unos 12 $\mathrm{m}$, del cual desconocemos si circunda la casa por el norte a modo de deambulatorio perimetral o si constituye una parte interna de la vivienda. No obstante, hay otros elementos constructivos más concretos que revelan un cierto esmero en el acabado interior. En primer lugar, la entrada al edificio está señalada por el mejor de los umbrales del poblado, un enlosado de piedra calcarenita muy bien alisada, en un vano de casi $2 \mathrm{~m}$ que da acceso a una amplia estancia cuadrada VIIC3, equipada únicamente con un banco de losas idénticas al umbral, también con la superficie muy trabajada y un ancho adecuado para sen-

15. Para una valoración comercial de dicho ajuar, véase Abad et alii, 2003. tarse en él; no parecía estar revestido de arcilla como se hace con los utilizados en funciones domésticas. Esta estancia sólo se comunica con una segunda, VIIC1, cuyo suelo se encuentra un tanto sobreelevado mediante un relleno de tierra y piedra que, junto al empedrado de guijarros de arenisca superpuesto, constituyen un excelente preparado para preservar el espacio de la humedad ascendente.

En otro trabajo, hemos sugerido la idea de un edificio público o de representación (Abad et alii, 2001, 169), principalmente por la rareza de su planta y porque la función doméstica está claramente descartada. Los materiales arqueológicos, de nuevo, son muy escasos y nada significativos. Los términos en que planteamos el presente análisis obliga a ser todavía más cautos en la identificación del edificio.

\section{UNA APROXIMACIÓN SOCIAL A LA ARQUITECTURA DOMÉSTICA DE EL ORAL}

Por oposición a las casas simples de dos estancias de El Oral, las casas que acabamos de revisar presentan, además de su tamaño, algún elemento constructivo relevante que las destaca en el conjunto urbano; sin embargo, son las casas con patio adosadas a la muralla oriental las que, a nuestro juicio, pueden recibir el calificativo de "residencias privilegiadas" y ser consideradas las viviendas de las elites.

Preparados de suelo a base de enlosados de adobes o empedrados de guijarros, suelos consistentes de arcilla rojiza, buenos enlucidos interiores, pintura mural, etc. acondicionan las estancias y otorgan una evidente prestancia al edificio. Pero, sobre todo, es la propia concepción de la casa compleja lo que nos hace decantarnos definitivamente por esta calificación, concepto en el que resulta primordial el desagüe de los patios atravesando el lienzo de la muralla para evacuar a extramuros. Aparte de la novedad que representa respecto a la arquitectura protohistórica del sureste, construir un conducto de desagüe en la hilada de base de la muralla adquiere una enorme significación, pues indica que en el mismo momento de proyectar la fortificación ya se sabía que ese preciso lugar iba a ser destinado a una vivienda de grandes dimensiones, provista de un patio o área descubierta central; es decir, existió un reparto previo del espacio urbano. Es un dato de suma importancia porque, además, revela de manera objetiva no sólo un grado de planificación urbana mucho mayor del que ha- 
bíamos imaginado, sino también el control de dicha planificación por un grupo destacado de la comunidad, hechos en los que deberemos incidir en el futuro.

La presencia de estas casas complejas durante la fase ibérica antigua en la zona de la desembocadura del río Segura conduce la discusión hacia una doble perspectiva: la propiamente constructiva, por un lado, y la lectura social que de su existencia se deriva, por otro.

Desde el punto de vista constructivo, se debe tener en cuenta, ante todo, que las casas con patio se conciben como una construcción hacia el interior y pocas aberturas al exterior. Así, su organización garantiza privacidad sin perjuicio de unas excelentes condiciones de habitabilidad, dado que el espacio abierto ofrece la luz y la aireación necesarias al resto de las habitaciones. La aparición de esta casa se puede explicar, en parte, por razones medioambientales, las mismas que explican el modelo genérico de casa 'mediterránea' y, desde esta óptica, no sería necesario buscar influencias o prestaciones directas de otras arquitecturas mediterráneas para argumentar su presencia en un poblado ibérico del sureste peninsular en el s. V a.C. Por ello, creemos lógico y normal que, en buena parte del Mediterráneo antiguo occidental, en un momento u otro, se haya podido desarrollar un tipo de casa organizada en torno a un patio. Son, a nuestro juicio, manifestaciones particulares en diferentes regiones mediterráneas de un mismo patrón de construcción doméstica, derivado de alguna manera del antiguo modelo de casa mesopotámica que se remonta al III milenio. La edilicia privada púnica de época helenística de Cartago (Lancel et alii, 1982; Lancel, 1994; Rakob, 1991), Kerkouan (Fantar, 1985; 1990) y Solunto (Italia y Lima, 1987) ofrece muy buenos ejemplos de ello y, por supuesto, la arquitectura doméstica griega, tanto en el ámbito oriental (Pesando, 1987) como en la Magna Grecia y Sicilia ${ }^{16}$. Decía Fusaro en su trabajo de 1982, todavía básico, que la aparición en el tejido urbano del ámbito griego del tipo de casa a pastàs, o su posterior evolución en la de patio, eran el reflejo de las transformaciones hacia una mayor parcelación social, consecuencia de la mejora económica del ciudadano y de sus ciudades (Fusaro, 1982, 24), además de la expresión inicial de una diferenciación por sexos de los espacios domésticos (Fusaro, 1982, 10 -

16. Esta última sistematizada en el Coloquio de Lecce de 1992 (D’Andria y Mannino eds., 1996). Véanse los trabajos generales de De Miró y de Barra Bagnasco en esta publicación.
12). Por ello, de entre todos los ejemplos que hemos citado, para nuestro discurso adquieren un especial interés las casas con patio del s. II a.C. de Lattes, en el Languedoc (Py, 1996, 204-206, 212-215), por cuanto representan la asunción de un tipo de casa y de una distribución funcional extraña al hábitat protohistórico tradicional galo (Garcia, 1994, 167). De otro lado, las excavaciones continuadas en centros indígenas de la Magna Grecia y Sicilia están dando a conocer un buen número de estos grandes edificios residenciales con patio, algunos del s. $\mathrm{V}$ y la mayoría del s. IV a.C., inspirados en la arquitectura doméstica griega, que vinculan a los grupos familiares de prestigio (Russo, 1996, passim). En el mundo protohistórico mediterráneo occidental, la aparición de la casa con patio tiene que ver, por tanto, entre otros motivos, con el deseo de una elite emergente por acceder a un estilo de vida diferente al de la mayoría, según se pone de manifiesto con claridad en Lattes o en la arquitectura indígena de la Península Itálica. Ahora bien, lo que nos llama la atención del ejemplo francés es que la materialización doméstica de dichas transformaciones sociales haya tenido lugar tan tarde, transcurridos más de cuatro siglos de contacto con el mundo colonial foceo (Garcia, 1994, 169), pero no cabe la menor duda de que éstos han sido los impulsos externos.

Puesto que en la arquitectura protohistórica del sureste peninsular no se han constatado los elementos constructivos embrionarios que conducen a las casas con patio de El Oral, este tipo de arquitectura doméstica debe verse como una verdadera novedad, lo que nos lleva a tener en cuenta la posibilidad de esos impulsos externos a los que nos acabamos de referir. No sólo los patios con desagüe carecen de precedentes. En realidad, la ausencia de referencias más antiguas se hace extensiva al propio concepto de casa compleja. El registro de asentamientos como Penya Negra, Saladares, Librilla y Benimaquía muestra la adopción de técnicas constructivas nuevas desde el s. VII aC (planta cuadrangular, combinación del zócalo de mampostería y alzado de adobe...) (Díes, 2001, 105), pero no del urbanismo orientalizante con edificaciones complejas. En Penya Negra, por ejemplo, las plantas cuadradas conviven con los fondos de cabaña (Díes, 2001, 105) y, a pesar del desarrollo económico alcanzado por este poblado, la arquitectura de la fase orientalizante ofrece un aspecto inhomogéneo, tal y como reconoce su excavador (González Prats, 2001, 177), que viene dado por un ambiente de casas simples de plantas cuadrangulares irregulares, de una sola 


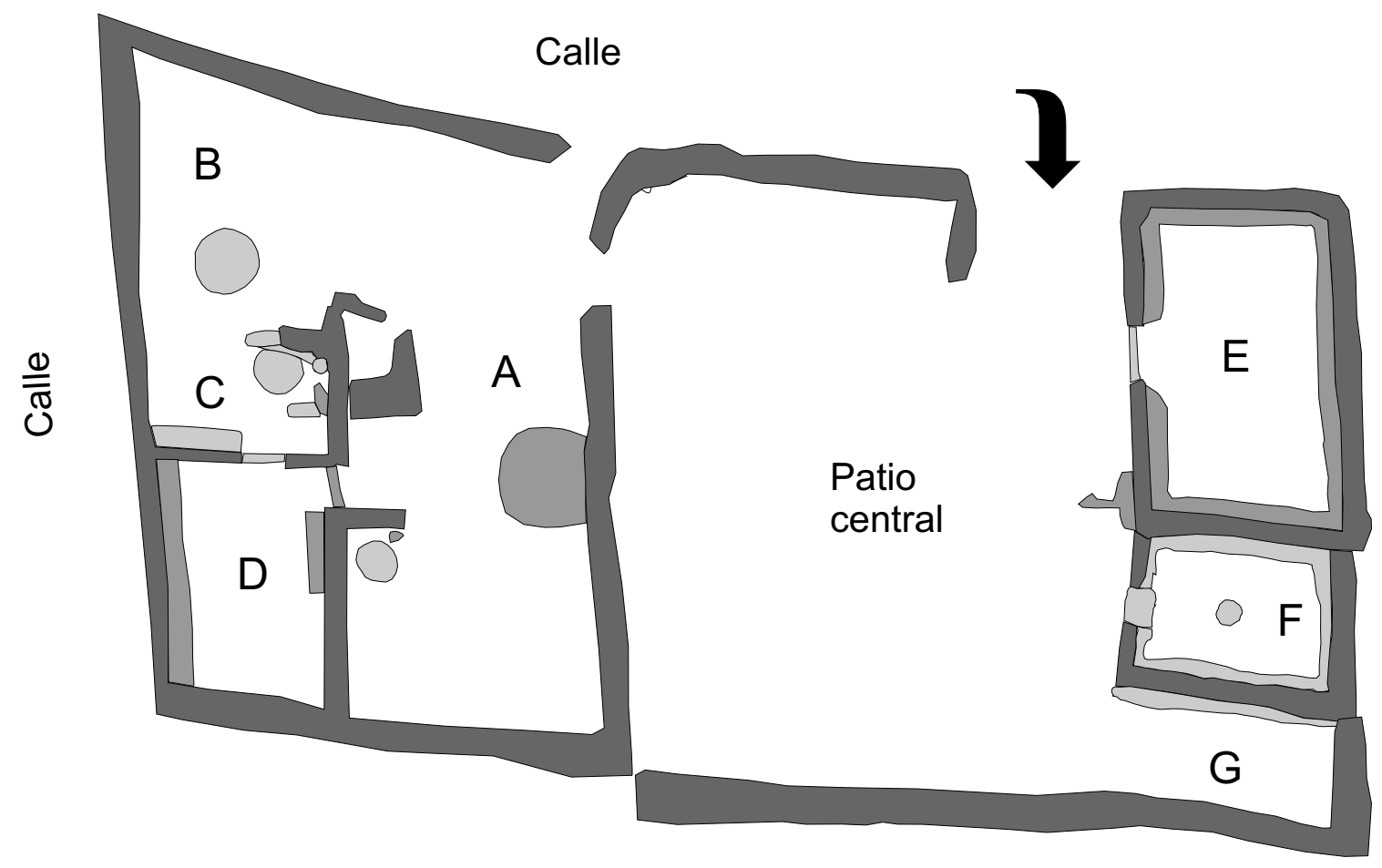

Calle

\begin{tabular}{l}
$0 \quad 2 \mathrm{~m}$ \\
\hline
\end{tabular}

Figura 8: Edificio de Los Almadenes.

estancia, no organizadas por calles ni manzanas, ni siquiera en los sectores llanos susceptibles de una ordenación urbana más regular (González Prats y Ruiz, 1990-91, 69). En la fase II de La Rábita, en la primera mitad del s. VII a.C., encontramos un edificio de tapial algo más complejo, entendido así por presentar un número mínimo de 11 habitaciones, cuya distribución tiene paralelos en los edificios fenicios de Chorreras, Morro de Mezquitilla o Toscanos ${ }^{17}$. Sin embargo, arrasado este edificio, las siguientes construcciones domésticas en el sitio ya no siguen este modelo y vuelven al tipo tradicional de vivienda, de una 0 dos estancias ${ }^{18}$. También durante la primera mitad del s. VI a.C., las construcciones de Benimaquía, tanto las viviendas como las de uso

17. El edificio no ha podido ser excavado en su totalidad, por lo que se desconoce su tamaño y distribución completa. Para el estudio de la técnica constructiva, véase Belarte y Gailledrat, 2003.

18. Tampoco se conservan las fábricas, ya que en las construcciones de la segunda mitad del s. VII a.C. desaparece el tapial, siendo sustituido por la técnica de zócalo de piedra y alzados de adobe. artesanal, son similares a éstas en cuanto a su tipología sencilla y la fábrica empleada. En el interior del sureste, y en las mismas fechas, un edificio de gran tamaño en el poblado de Los Almadenes (Hellín, Albacete) podría ser la excepción, pero no fue concebido como de planta compleja sino que su mayor extensión es consecuencia de haber integrado varias unidades domésticas sencillas, mediante la construcción de una valla que crea un espacio abierto intermedio a modo de patio (López Precioso y Sala, 1999; Sala y López Precioso, 2000) (Figura 8).

Ante este panorama, no podemos sino adoptar las conclusiones de E. Díes $(2001,106)$ quien, tras el análisis de la arquitectura fenicia y protohistórica del sureste, asegura que con la documentación actual no se puede defender una aculturación completa en el sureste, al menos en términos arquitectónicos, ni siquiera que la población fenicia fuera muy numerosa, aunque no descarta una presencia esporádica de comerciantes o artesanos fenicios en puntos como Penya Negra o Saladares. En consecuencia, creemos que el registro arquitectónico de los siglos VII y primera mitad del s. VI a.C. refleja 


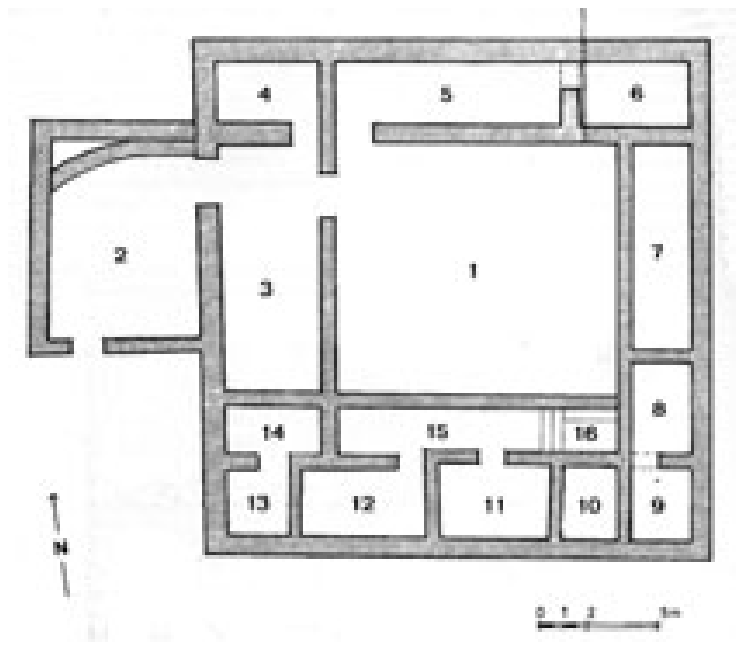

$1^{\mathrm{a}}$ fase

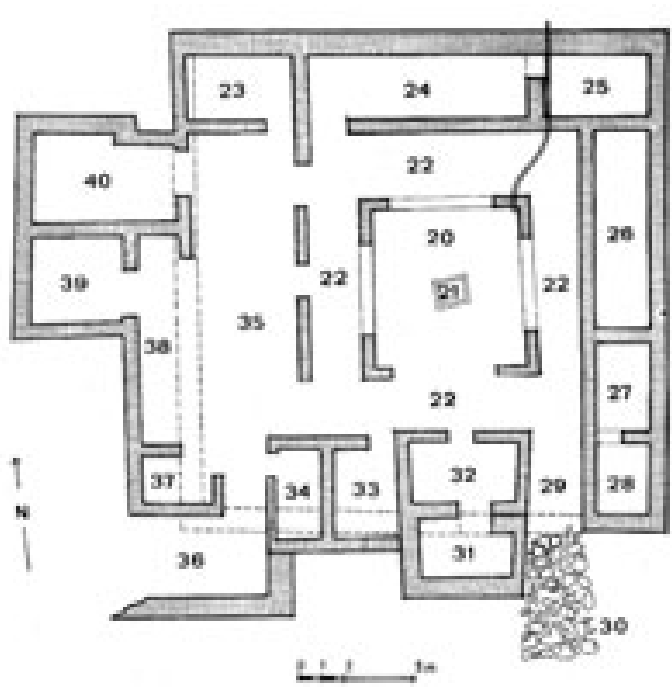

$2^{\mathrm{a}}$ fase

Figura 9: Fases constructivas en el edificio fenicio de Abul (elaboración propia a partir de Mayet y Tavares da Silva, 2001).

un contexto de asimilación de nuevos elementos constructivos que, sin embargo, no ha alcanzado el estadio de transformación social que supone la reorganización del hábitat y la adopción de nuevas formas urbanas, ajenas a la tradición.

En cambio, este estadio es el que sí observamos en el urbanismo y en las casas complejas de El Oral, a fines del s. VI a.C., porque es ahora, y no antes, cuando se documenta la prueba palpable de la emergencia de una elite social, que escenifica su poder en el ámbito doméstico a través de sus viviendas. Ahora bien, la casa IVH (Figura 5), que hemos catalogado como una residencia privilegiada, presenta una planta bastante racional, imposible de explicar por un paulatino proceso de mejora de la vivienda tradicional, a medida que van progresando las circunstancias socioeconómicas de la población protohistórica. Hay que retomar la idea ya mencionada de los impulsos externos, capaces de modificar rápida y ostensiblemente una situación, para empezar a comprender por qué este edificio sin precedentes en el sureste rompe con todo lo anterior, y se asemeja de manera notable al edificio del s. VII a.C. del establecimiento fenicio de Abul, en el estuario del río Sado en Portugal (Mayet y Tavares, 2001, 249 ss.) (Figura 9). Dicho edificio y la casa IVH, pese a la diferencia de tamaño entre ambos, comparten rasgos constructivos esenciales, como la planta cuadrada con unos muros maestros perimetrales de mayor envergadura, un acceso indirecto a través de un vano simple, la organización de los espacios interiores en torno a un patio central, cuyo desagüe se mantiene tras las reformas, la combinación de estancias cuadradas menores en un lateral y estancias mayores en otras alas y la aparición en la segunda fase de una estructura menor de difícil interpretación en el centro del patio.

No es fácil dilucidar los motivos por los que una casa ibérica de finales del s. VI a.C., o inicios del $V$ a.C., guarda tantos parecidos con una casa fenicia del s. VII a.C. situada en el extremo opuesto de la Península Ibérica. Pero sí podemos asumir la lectura social que su aparición en el sureste de época ibérica conlleva, es decir, la consecuencia final de la puesta en marcha de los mecanismos del cambio social. En este punto, ha quedado claro que en el sureste, como en otros ámbitos del Mediterráneo antiguo, la aparición de la casa compleja significa la instauración definitiva de un panorama social también más complejo, como ya señaló Fusaro (1982) para la arquitectura doméstica griega, o como hemos visto en Lattes. No obstante, de entre todos los ámbitos mediterráneos señalados, nos decantamos por el mundo etrusco, por observar en él unas interesantes analogías constructivas, que nos pueden ayudar a entender la arquitectura doméstica monumental del sureste ibérico.

En Etruria, los grandes edificios con patio de Murlo y Acquarossa, considerados los "pala- 
cios" de las aristocracias etruscas en los siglos VII y VI a.C., constituyen la dimensión doméstica y urbana de lo que en el orden funerario representan las monumentales tumbas orientalizantes etruscas y sus ricos ajuares (Torelli, 1996, 83$88)^{19}$. Socialmente son el exponente del triunfo de la aristocracia gentilicia clientelar, cuya exaltación en el mundo de los vivos aparece escenificada en el programa iconográfico que ornaba estas regias etruscas ${ }^{20}$.

La cuestión que nos planteamos ahora es si este proceso se produce al mismo tiempo en el sureste de la Península Ibérica. Y, a nuestro juicio, y de acuerdo con el registro arqueológico que estamos analizando, la respuesta ha de ser negativa. En ambos casos, el origen es similar y paralelo: los estímulos, que una población foránea, a través de las relaciones comerciales, provocan en la población del Bronce Final, ponen en marcha unas transformaciones socioeconómicas sustentadas en el atesoramiento, por un lado, y el control de los objetos de comercio y de la producción económica, por otro, por parte de un grupo. Además, la actividad comercial fenicia en el sureste peninsular incide sobre un poblamiento que cuenta ya con asentamientos estables desde el s. IX a.C., como consecuencia del notable desarrollo alcanzado en la zona durante la Edad del Bronce, de entre los que destacamos el Cabezo Redondo de Villena (Soler, 1992; Hernández, 2001), tanto por la calidad de la arquitectura doméstica como por la distribución ordenada de las construcciones mediante calles y terrazas en un urbanismo en ladera. Pero, a partir de aquí, el proceso sigue ritmos divergentes $y$, mientras que en Etruria en el s. VII a.C. ya encontramos unas estructuras sociales transformadas, cuyo poder se manifiesta en la ostentación pública del mismo, tanto en el mundo de los vivos como en el mundo de los muertos, el registro arqueológico de la zona alicantina no ofrece indicios claros en este sentido. En el alto Vinalopó, el abandono del Cabezo Redondo interrumpe el proceso de atesoramiento por parte de una elite, magníficamente representado por el Tesoro de Villena y el tesorillo del Cabezo Redondo, que hubiera

19. La casa con patio continúa en el s. V a.C., con buenos ejemplos en el enclave colonial etrusco de Marzabotto, y pasa a considerarse el antecedente de la casa romana con atrio (Donati, 2000, 328-329).

20. Algunas de estas regias han sido redescubiertas al cambiar la interpretación de antiguos hallazgos de conjuntos escultóricos como edificios palaciales en lugar de templos. Véase un reciente estado de la cuestión en Torelli, 2000 . desembocado en un sistema aristocrático gentilicio clientelar, pues las prospecciones arqueológicas en la comarca constatan un vacío en el poblamiento durante los siglos VII y VI a.C., que sólo empieza a recuperarse tímidamente a partir de mediados del s. V a.C. ${ }^{21}$. Respecto al otro gran poblado, Peña Negra, creemos que merece ponerse en cuarentena su paralelismo con los poblados tartésicos, aceptado por la mayoría de los investigadores, en cuanto a ser sede del inicio de las transformaciones sociales, pues no cumple muchos de los rasgos que se han dado como condiciones necesarias: no es tan extenso como se ha publicado ${ }^{22}$; la hipotética muralla corresponde a la fase II, por tanto, del s. VI a.C.; la arquitectura doméstica no va más allá de casas sencillas de ubicación desordenada.

$Y$ si nos detenemos en el mundo funerario, comprobaremos que no existen tumbas monumentales en este período. En la necrópolis de encachados del Bronce Final de Penya Negra, el mantenimiento de las pautas rituales desde la fase más antigua, que se inicia en el s. IX a.C., a la fase más reciente, que acaba en el 625 a.C. (González Prats, 2002, 263-277), no parece reflejar una evolución de la estructura social. Los enterramientos se suceden en el transcurso de ambas fases sin cambios en los ajuares, que son en todo momento sencillos y austeros; no aparecen armas ni elementos objetivos de riqueza, es decir, no se dan aquellos primeros signos de estratificación social que ya se observan en el periodo Villanoviano II, en el s. VIII a.C., con la aparición en los ajuares de elementos metálicos -objetos de adorno personal y vasos de bronce-, armamento e importaciones raras -copas geométricas griegas y objetos de uso personal de fayenza de fabricación egipcia o egiptizante- (Torelli, 1996, 52), y que también refleja la necrópolis tartésica de La Joya en el ámbito peninsular (Garrido, 1970; Garrido y Orta, 1978). La existencia de tumbas con encachados entre una mayoría de sencillas tumbas en hoyo refleja, en efecto, una estructura gentilicia, pero la isonomía de los ajuares y su pobreza no permite presupo-

21. Los testimonios de esta época se reducen a la necrópolis del Peñón del Rey (Hernández Alcaraz, 1997), algunas cerámicas ibéricas y copas áticas del último cuarto del s. V a.C. en el entorno de la laguna de Salinas (Hernández y Sala, 1996) y la leona del Zaricejo (Soler, 1972; Chapa, 1985, 53).

22. Tras el reconocimiento del terreno y su comparación en los mapas topográficos, J. Moratalla e I. Grau (Abad et alii, 2001, 190) proponen una extensión de 14-15 Ha de un hábitat disperso. 
ner ni el atesoramiento de riqueza por parte de un grupo, ni el funcionamiento de unas prácticas de servidumbre. Se puede decir, por tanto, que los usos funerarios de la necrópolis alicantina no reflejan desequilibrios económicos y sociales. En cambio, la necrópolis orientalizante de Les Casetes, recientemente descubierta en la localidad costera de La Vila Joiosa, sí ofrece los primeros indicios de una voluntad de acaparar riqueza en los ajuares de una treintena de enterramientos, datados entre finales del s. VII y mediados del s. VI a.C. Sus ajuares continúan estando constituidos por pocas piezas -objetos personales y vasos contenedores de ofrendas-, pero ya incluyen objetos exóticos procedentes del comercio exterior, como una cantimplora egipcia de fayenza y amuletos de la misma procedencia, orfebrería fenicio-púnica, y las primeras puntas de lanza; la infraestructura de las tumbas es en su mayoría sencilla, lo que hace destacar una extraña tumba de pozo de planta cruciforme sobre las demás, y se documentan algunas señalizaciones, como encachados tumulares rodeados por un mosaico de cantos rodados, que también acrecientan el significado social de las tumbas que las ostentan (García Gandía, 2001).

Así, pues, todo parece indicar que, una vez en marcha ambos procesos de diferenciación social, la velocidad se ralentiza en el sureste peninsular y la estructura gentilicia primaria se perpetúa. Así lo entendemos desde el ámbito de la arquitectura al constatar, como ya se ha dicho, que pese a la asimilación de algunos elementos culturales, técnicas constructivas en este caso, no se adopta el urbanismo orientalizante con edificaciones complejas, luego es posible que tampoco de las estructuras sociales que lo generan. Por todo ello, nos parece que el proceso sociopolítico de emergencia y exaltación de las aristocracias gentilicias clientelares, que en Etruria, por seguir con el ejemplo, se gesta en el s. VIII, se desarrolla desde el s. VII y alcanza su máxima expresión durante el s. VI a.C., tiene lugar en esta zona del sureste cien años después: se desarrolla en el s. VI a.C. para alcanzar su culminación durante la fase ibérica antigua ${ }^{23}$. Ésta puede ser la explicación de las casas con patio de El Oral, en las que queremos ver el trasunto arquitectónico de los palacios aristocráticos etruscos de Murlo y Acquarossa en el mundo ibérico. Serían, pues, las residencias de las elites,

23. Para M. Bendala $(2001,23)$, el punto de inflexión en el proceso de maduración de las culturas urbanas del levante peninsular también se situaría en el s. VI a.C. encabezadas por la casa IVH de la que, desde ahora, podemos admitir su función palacial. En el mundo funerario, es asimismo durante el periodo ibérico antiguo cuando aparecen los primeros elementos objetivos de distinción de los linajes aristocráticos, lo que se manifiesta a través de la monumentalización de algunas tumbas ${ }^{24}$, que en la Contestania corresponden a los pilares-estela y los monumentos turriformes, y a través de la necesidad de estatuaria mayor para enfatizar la distinción de los allí enterrados. Es en este contexto ideológico donde adquiere pleno sentido la concepción de la escultura como delimitador del territorio, a través de la identificación de los grupos aristocráticos de varios asentamientos con un mismo símbolo (Chapa, 1996) ${ }^{25}$. En consecuencia, la escultura funeraria ibérica contestana se convierte en el reflejo iconográfico de la existencia de un referente histórico imprescindible para la identificación de las sociedades urbanas (Bendala, 2001, 20).

Son, en definitiva, procesos históricos similares, que se desencadenan al unísono en espacios geográficos distintos, pero continúan en marcos temporales variables, no aplicables por igual en todos los territorios de la cuenca mediterránea. Así se entiende que en el hábitat lucano de Roccagloriosa aparezca durante el s. IV a.C. una residencia gentilicia con un oikos votivo en el patio, que sus excavadores comparan socialmente con los anaktora de Murlo y Acquarossa, pese a la diferencia cronológica (Gualtieri, 1996, 306). En el sur de la Península Ibérica, A. Ruiz (1996, 62-63) reconoce la existencia de tres áreas distintas en el proceso de definición de la ideología aristocrática: el núcleo tartésico-gaditano costero del Bajo Guadalquivir, por un lado, y el valle del Guadalquivir medio, por otro, ambos con un proceso iniciado a fines del s. VIII o principios del s. VII a.C., y una tercera área en la zona extremeña donde la construcción del palacio-santuario de Cancho Roano en el s. VI a.C. señala el retraso de la consolidación del proyecto aristocrático hasta dicho siglo. Que en la franja mediterránea peninsular ocurre con retraso lo confirman otras evoluciones socio-económicas y políticas parecidas. Entre las comunidades protohistóricas de la costa catalana, J. Sanmartí y C. Belarte señalan dos momentos claves en la trayectoria hacia estructuras estatales. El prime-

24. Véase una valoración similar en Santos, 1998, 401-402.

25. La idea de la identificación del grupo aristocrático en un icono escultórico ha sido ampliamente razonada en sendos trabajos recientes de A. Ruiz y A. Sánchez (2003) y T. Chapa (2003). 
ro, en la segunda mitad avanzada del s. VII a.C., en buena medida a causa del impacto comercial fenicio sobre una población descentralizada, supone la aparición de los primeros asentamientos estables, cuyo modelo de casa sigue siendo una vivienda sencilla con una sola estancia polifuncional, y sólo la incipiente especialización funcional de dichos asentamientos refleja los primeros signos de jerarquización social (Sanmartí y Belarte, 2001, 164-165). A mediados del s. V a.C. y principalmente en los siglos IV-III a.C. es cuando se alcanza el final del proceso, lo que se materializa en sistemas complejos de ordenación del territorio centralizados en grandes centros fortificados de entre 4 y $10 \mathrm{Ha}$, de un lado, y en la existencia de viviendas destacadas en los mismos, de otro lado, para las que tampoco se descarta una función palacial (Sanmartí y Belarte, 2001, 166-168).

A un resultado similar desde el punto de vista arquitectónico se llega en la Alta Andalucía cuando, tras la reorganización del territorio a partir de los grandes oppida ibéricos, Puente Tablas (Jaén) presenta, por primera vez en el s. IV a.C., casas complejas cuyas diferencias en tamaño y planta se interpretan como el signo de vínculos clientelares entre sus moradores (Ruiz, 1994, 150; 1998a, 82, 84; 1998b, 292).

Si centramos nuestra visión en el poblado de El Oral, también aquí se percibe la jerarquización social a partir de las diferencias entre los tipos de casas, ahora todavía más evidentes con el marcado contraste entre los edificios con patio y el modelo más sencillo de casa con doble estancia. Sin embargo, no encontramos un reparto diferencial del espacio urbano en función de dichas relaciones clientelares, al menos de un modo tan claro como el que refleja el urbanismo de Puente Tablas, con un sector del oppidum reservado para la residencia del aristócrata principal (Ruiz, 1998a, 84). En El Oral, en lo que conocemos hasta ahora, y aunque las casas complejas con patio aparecen concentradas en el perímetro oriental del poblado, no podemos hablar de un área urbana reservada para los segmentos aristocráticos de mayor poder, pues las casas complejas, con o sin patio, siguen siendo vecinas de las sencillas (Figura 3). De esta manera, podemos sospechar algún vínculo clientelar o parental entre los moradores de las casas sencillas, IVE y IVF (Figura 10), adosadas al complejo palacial IVH por el sur, pero no encontramos una repuesta satisfactoria para la ubicación de los restantes tipos de casas. Por ejemplo, las casas IIIG y IIIK, a las que más arriba hemos dedicado nuestra atención por tratarse de construcciones complejas y de extensión destacable, aunque sin patio central, se encuentran frente a la casa palacial IVH, al otro lado de la calle. No obstante, es cierto que la mayoría de las construcciones sencillas de dos estancias (casas IIB, IIC-D, IIIC y IIID) se sitúan al norte de las casas complejas.

Las diferencias sociales también pueden observarse a través de la distinta articulación del espacio doméstico entre las viviendas pequeñas, con rígidos esquemas de uso, y las grandes casas con patio, donde es posible una mayor flexibilidad en el tránsito, función y especialización del espacio habitado. Como ha sugerido recientemente L. Nevett a propósito de la casa griega (Nevett, 1999, 154-175), las grandes casas permiten la segmentación del grupo familiar e incluso una especialización de género para los espacios, ya que pueden separar físicamente diversos rangos de actividades e individuos, entre las que destacaría la aparición de la estancia de representación -el andrón en el mundo griego-, que permite mantener al visitante al margen de la actividad doméstica en las ocasiones sociales que así lo requieran. Es la misma perspectiva que M.P. Allison $(1999,11)$ aplica a la arquitectura doméstica en general, a cuyo estudio accede desde la compartimentación de espacios de género y su implicación en atribuciones funcionales o culturales. En este sentido, El Oral, con 19 unidades constructivas identificadas, sencillas y complejas, ofrece una excelente documentación susceptible de ser analizada desde este punto de vista.

Aparte de la lectura de género de los espacios construidos, los nuevos entornos domésticos que ofrece la vivienda articulada en torno a patios apuntan directamente al incremento de la importancia del individuo en su relación con la comunidad, así como al desarrollo de la noción de vida privada separada de la vida de la comunidad (Nevett, 1999, 154-175). Estas grandes casas aseguran la privacidad al garantizar el control del acceso visual y del acceso espacial a determinados ámbitos preservados a la intimidad (Sanders, 1990, 49-50), lo que nos remite a nuevas pautas de conducta social y comunicativa. En términos sociales, se trataría del aislamiento por parte de un segmento de la sociedad, a través de sus pautas de comportamiento, buscando distinguirse del resto de la sociedad y, a su vez, controlar las relaciones con la misma. Hace unos años, A. Rapoport ya propuso la relación de la casa de patio con la necesidad de privacidad, y estableció la separación de ámbitos privados y públicos como un elemento multicultural propio de sociedades de carácter jerárquico, proponien- 


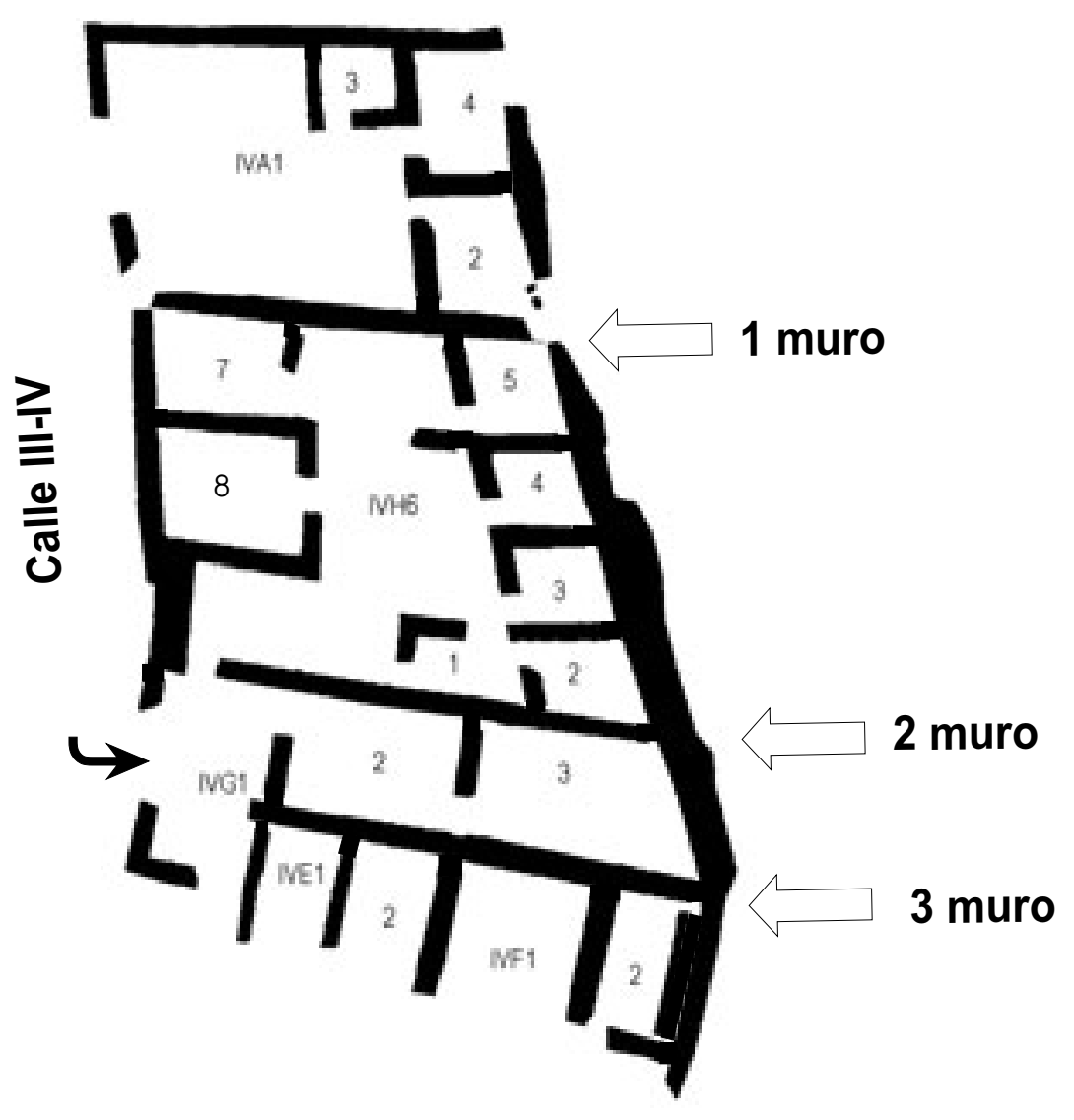

Figura 10: Relaciones entre los muros maestros y divisores del barrio IV de El Oral.

do ejemplos en Grecia, Roma, el Islam, la India, Latinoamerica o los Jan de China (Rapoport, $1969,65-81)$. Por todo ello, creemos que la presencia de las viviendas con patio en El Oral en época ibérica antigua refuerza el incremento de la desigualdad social entre los grupos privilegiados y el resto de la comunidad.

La nueva estructura social ibérica fundamenta en parte las relaciones clientelares sobre una base religiosa, concretamente en la vertiente del culto a los antepasados del señor, mecanismo que asegura el crecimiento de la gens aristocrática y mantiene el poder de un segmento de la sociedad, además de constituirse en un referente de cohesión (Ruiz y Molinos, 1993, 264) ${ }^{26}$. Los ejemplos etruscos de Murlo, con su gran patio reservado para celebraciones religiosas multitudinarias de tipo gentilicio que, de esta manera, son controladas por el áristos, o de Acquarrosa, con

26. Véase una reciente reflexión sobre el grupo clientelar entre los iberos en Ruiz, 1998b. su edificio templario ahora separado de la regia pero todavía bajo su control, nos hacen barajar la posibilidad de que también entre los iberos del s. V a.C. del sureste peninsular pudiera existir este nexo físico entre el palacio y el edificio de culto. Así nos lo sugiere en El Oral, aunque con muchas reservas, la relación entre la casa palacial IVH y la casa contigua IVG.

Aunque publicadas como dos unidades de habitación independientes (Abad et alii, 2001, 59-83), la reflexión que hacemos en este trabajo nos induce al replanteamiento del vínculo entre ambas construcciones, y ello por varias razones. Un primer dato relevante es que los muros maestros, que nos han servido para destacar la casa IVH por estar construidos con una fábrica mejor y un ancho mayor que en los restantes edificios del poblado, también incluyen a IVG (Figura 10). En realidad, ambas unidades constructivas se integran en un solo espacio delimitado por tres largos muros, que discurren paralelos en sentido este-oeste desde la calle III-IV al lienzo oriental de la muralla. De hecho, en un primer momen- 
to entendimos que se trataba de una sola edificación y, sólo tras resolver que la circulación interna era independiente en ambos y comprobar estratigráficamente que la estancia IVG1 fue construida con posterioridad, los diferenciamos como dos unidades distintas unidas en un segundo momento con la edificación de IVG1. Para ello, se tomaba de nuevo espacio público de la plazoleta existente frente a las puertas. Integrar dos construcciones hipotéticamente domésticas de esta manera siempre nos pareció algo insólito, pero no cabía la menor duda acerca del vínculo entre ambas.

Sin embargo, la función doméstica de la casa IVG nunca ha estado del todo clara. Tiene una forma estrecha y alargada, poco apropiada para el quehacer doméstico en cuanto a luz y aireación, condiciones que empeoran al construir IVG1, pues dicha reforma debió dejar la estancia zaguera, IVG3, en penumbra o prácticamente a oscuras. Tampoco las estructuras y el ajuar encontrados en las estancias se pueden adscribir a un ambiente doméstico. No existe hogar alguno, por ejemplo, y el ajuar cerámico de IVG2 estaba constituido por un conjunto cerámico bastante curioso: una urna bicónica entera al lado de tres ánforas y un lebes, seccionados longitudinalmente para conformar un recipiente cóncavo, y apilados sobre el suelo junto a la esquina de una gran plataforma cuadrada de barro ${ }^{27}$. Los suelos de las habitaciones aparecieron completamente limpios, sin el menor resto de las capas de desechos tan características de los ambientes domésticos y de cocina. Además, y pese a encontrarse casi a oscuras, IVG3 se encuentra especialmente acondicionada: la puerta presenta un umbral sobreelevado de adobes, con un peldaño de acceso en IVG2 y otro de bajada en IVG3; una gruesa capa de tierra arcillosa como pavimento, colocada sobre un estrato de gravas mezcladas con un material arenoso para favorecer el drenaje de la humedad subyacente; las paredes estaban enlucidas y pintadas con los colores rojo vinoso y ocre; el techo también pudo estar pintado de rojo ${ }^{28}$; y por último, en el centro de la estancia se encuentra una estructura rectangular construida con adobes, sin huellas de fuego ni capa de cenizas asociada, que pudo funcionar como una mesa.

27. El otro medio lebes se encontró en la entrada del patio de la casa IVH. Véanse los detalles en Abad et alii, 2001, 59-65.

28. Así interpretamos unos fragmentos de enlucido pintado con improntas de caña en el reverso.
En IVG no encontramos elementos objetivos que señalen una función propiamente religiosa, como por ejemplo exvotos, restos de libaciones u ofrendas; sin embargo, por todo lo expuesto más arriba, no parece descabellado proponer una función especial para IVG, con un cometido estrechamente asociado al grupo familiar que habita en IVH. De este modo, relacionar IVG, en especial la estancia zaguera IVG3, con un espacio de reunión de los representantes de otros grupos familiares, vinculados mediante relaciones clientelares, para el ritual de reconocimiento del antepasado del áristos o, sencillamente, un lugar para la celebración de reuniones favorecedoras de la cohesión social entre las elites y entre las elites y el resto de la comunidad, nos parece una hipótesis sugerente, pese a que resulta indemostrable hoy por hoy con los datos disponibles.

La "casa de los ídolos", en el complejo de templos de Micenas, también constituye una sencilla construcción de dos habitaciones, con una mesa similar a la de IVG3 en la habitación del fondo, allí acompañada de unos pequeños bancos corridos que sostenían un conjunto de figuras; una reforma posterior añade una habitación más en la entrada, lo que la convierte en una construcción de tres estancias de disposición lineal (Hiesel, 1990, 19-20, Abb. 10). Aunque queda claro que la analogía entre el edificio ibérico y el micénico es imposible, el parecido formal, unido a la ambigüedad que separa lo religioso del poder temporal en el mundo antiguo, nos permiten, al menos, reiterar el incipiente conocimiento que poseemos sobre los edificios de representación pública y residencia de las elites en el mundo ibérico, a la vez que señala el largo camino por recorrer.

\section{CONCLUSIONES}

Tras veinte años de trabajo, en El Oral comenzamos a tener datos que nos permiten avanzar algunas hipótesis acerca de los componentes socio-económicos del poblado, de su relación entre la arquitectura y los elementos inmuebles y las gentes que allí vivían. Algo que se ve dificultado por la escasez de objetos muebles, por la falta de elementos que nos permitan documentar el significado y la función de cada una de las casas y las habitaciones. Sin embargo, creemos que estamos en condiciones de avanzar hipótesis acerca de la función no estrictamente doméstica de varias de estas edificaciones, algo que ya habíamos entrevisto, pero que ahora podemos ir 
precisando; por una parte, gracias al mejor conocimiento del poblado en general; por otra, gracias a los estudios que se están llevando a cabo en otros ámbitos del mundo ibérico en particular y del mundo mediterráneo en general, que nos ofrecen anclajes en los que apoyar la elaboración de nuestras hipótesis.

El Oral, poblado modesto donde los haya, se manifiesta una vez más como un lugar de cruce, de mezcla, de mestizaje, como un hito en la evolución que lleva de lo oriental al mundo ibérico. Es un importante eslabón en el proceso entre el período orientalizante y la época ibérica, bien situado en las rutas que desde la costa llevan al interior, con un modelo económico autosuficiente en lo que a actividades primarias se refiere y con un papel primordial en lo relativo a intercambios y actividades comerciales.

Pero todo ello, que creemos ha quedado claro en las memorias y artículos publicados con anterioridad, se comienza ahora a vislumbrar en lo que se refiere a los ambientes domésticos y urbanos; comienzan a entreverse las elites, las relaciones sociales, la evolución hacia una sociedad más compleja. A que la arquitectura, en suma, contribuya, a partir del conocimiento de nuestros humildes elementos materiales, al mejor conocimiento de los elementos superestructurales, sociales e ideológicos, de la cultura ibérica.

\author{
Profa. Feliciana Sala Sellés \\ Prof. Lorenzo Abad Casal \\ Area de Arqueología \\ Dpto. Prehistoria, Arqueología, $\mathrm{H}^{\mathrm{a}}$ Antigua, \\ Filología griega y Filología Latina \\ Facultad de Filosofía y Letras \\ Universidad de Alicante \\ Apdo. 99 \\ 03080 Alicante \\ feliciana.sala@ua.es \\ lorenzo.abad@ua.es
}

\section{BIBLIOGRAFÍA}

ABAD, L. y SALA, F., 1993: El poblado ibérico de El Oral (San Fulgencio, Alicante), T.V. del S.I.P., 90, Valencia.

ABAD, L. y SALA, F., 1997: «Sobre el posible uso cúltico de algunos edificios de la Contestania Ibérica», Quaderns de Prehistòria i Arqueologia de Castelló, 18, Diputació de Castelló, 91-102.

ABAD, L., SALA, F., GRAU, I., MORATALLA, J., PASTOR, A. y Tendero, M., 2001: Poblamiento ibérico en el Bajo Segura: El Oral (II) y La Escuera, Bibliotheca Archaeologica Hispana, 12, Real Academia de la Historia, Madrid.

ABAD, L., SALA, F., GRAU, I. y MORATALLA, J. 2003: "El Oral y La Escuera, dos lugares de intercambio en la desembocadura del río Segura (Alicante) en época ibérica", Reunión Internacional IV Jornadas de Arqueología suba- cuática. Puertos fluviales antiguos: ciudad, desarrollo e infraestructura, Universitat de València, 81-98.

ALLISON, P.M., 1999: "Introduction", en P.M. Allison (ed.): The Archaeology of Household Activities, Londres, 1-18.

AURENCHE, O., 1981: La maison orientale. L'Architecture du Proche Orient Ancien des origines au milieu du quatrième millénaire, París.

BARRA BAGNASCO, M., 1996: "La casa in Magna Grecia”, Actas del Coloquio Ricerche sulla casa in Magna Grecia e in Sicilia, Universidad de Lecce, Archeologia e Historia, 5, Congedo Editore, 41-66.

BELARTE FRANCO, C., 1996: "L'estudi de la casa protohistòrica a Catalunya i àrees adjacents: proposta tipológica $\mathrm{i}$ terminològica", Pyrenae, 27, 103-115.

BELARTE FRANCO, C., 1997: Arquitectura domèstica i estructura social a la Catalunya protohistòrica, Arqueo-Mediterrània, 1, Barcelona.

BELARTE FRANCO, C. y GAILLEDRAT, E., 2003 : «Murs Protohistoriques de terre massive sur la côte orientale de la péninsule ibérique (VIle - Ile s. av. J.C.) : l'exemple de Guardamar del Segura (prov. d'Alicante) », Echanges transdisciplinaires sur les constructions en terre crue, 1 , Table Ronde de Montpellier, 283-297.

BELÉN DEAMÓS, M., 2001: "Arquitectura religiosa orientalizante en el bajo Guadalquivir", en D. Ruiz y S. Celestino (eds.): Arquitectura oriental y orientalizante en la Península Ibérica, Madrid, 1-16.

BELÉN DEAMÓS, M. y ESCACENA, J.L., 1995: "Interacción cultural fenicios-indígenas en el Bajo Guadalquivir", Kolaios, 4, 67-101.

BENDALA GALÁN, M., 2001: "Procesos de poblamiento, urbanización y evolución social en Iberia: una introducción”, en L. Berrocal y Ph. Gardes (eds.): Entre celtas e iberos. Los poblamientos protohistóricos de las Galias e Hispania, Madrid, 19-28.

BERROCAL-RANGEL, L. y GARDES, Ph., (eds.) 2001: Entre celtas e iberos. Los poblamientos protohistóricos de las Galias e Hispania, Real Academia de la Historia-Casa de Velázquez, Madrid.

CARRIAZO, J. M., 1973: Tartessos y El Carambolo. Madrid.

CASARES, J., 1997: Diccionario ideológico de la Lengua española, ed. Gustavo Gili, Barcelona.

CASTELO RUANO, R., 1995: Monumentos funerarios del sureste peninsular: elementos y técnicas constructivas, Monografías de Arquitectura Ibérica, Madrid.

CHAPA, T., 1985: La escultura ibérica zoomorfa, Madrid.

CHAPA, T., 1996: "La escultura ibérica como elemento delimitador del territorio", Coloquio Internacional Iconografía ibérica, iconografía itálica: propuestas de interpretación y lectura, Varia 3, Universidad Autónoma de Madrid, 235-247.

CHAPA, T., 2003: "El tiempo y el espacio en la escultura ibérica: un análisis iconográfico", en T. Tortosa y J.A. Santos (eds.): Arqueología e Iconografía. Indagar en las imágenes, Roma, 99-120.

CHAZELLES, C.-A., 1996: "Les téchniques de construction de l'habitat antique de Lattes », Lattara, 9, Lattes, 259328.

D'ANDRIA, F., 1996: "La casa in Messapia", Actas del Coloquio Ricerche sulla casa in Magna Grecia e in Sicilia, Universidad de Lecce, Archeologia e Historia, 5, Congedo Editore, 403-438.

D'ANDRIA, F. y MANNINO, K. (eds.), 1996: Ricerche sulla casa in Magna Grecia e in Sicilia (Lecce, 1992), Universidad de Lecce, Archeologia e Historia, 5, Congedo Editore.

DE MIRÓ, E., 1996: "La casa greca in Sicilia”, Actas del Coloquio Ricerche sulla casa in Magna Grecia e in Sicilia, 
Universidad de Lecce, Archeologia e Historia, 5, Congedo Editore, 17-40

Diccionario de la Lengua Española, Edición electrónica versión 21.1.0, Real Academia Española de la Lengua, Madrid, 1992

DÍES CUSÍ, E., 2001: "La influencia de la arquitectura fenicia en las arquitecturas indígenas de la Península Ibérica (s. VIII-VII)", en D. Ruiz y S. Celestino (eds.): Arquitectura oriental y orientalizante en la Península Ibérica, C.S.I.C., Madrid, 69-121.

DíES, E. y ÁLVAREZ, N., 1998: "Análisis de un edificio con posible función palacial: la casa 10 de la Bastida de les Alcusses (Moixent)", Actas del Congreso Internacional Los Iberos. Príncipes de Occidente, Fundación La Caixa, Barcelona, 327-341.

DíES, E., BONET, H., ÁlVAREZ, N. y PÉREZ, G., 1997: "La Bastida de les Alcusses (Moixent): resultados de los trabajos de excavación y restauración. Años 1990-1995", A.P.L., XXII, 215-295.

FANTAR, M., 1985: Kerkouane. Cité Punique du Cap Bon (Tunisie). T. II, Architecture doméstique, Túnez.

FANTAR, M., 1990: "Les maisons puniques", L'habitat tradicionnel dans les pays musulmans autour de la Mediterrannée. T. II, L'histoire et le milieu, El Cairo, 325-332.

FULLANA, M., 1984: Diccionari de l'art i dels oficis de la construcció, Editorial Moll, Mallorca.

FUSARO, D., 1982: "Note di architettura domestica greca nel periodo tardo-geometrico e arcaico", Dialoghi di Archeologia, 1, 4, 5-30.

GARCÍA, D., 1994: "Une maison à cour de plan méditerranéen de la fin de l'Age du fer à Lattes ('îlot 9 au lle s. av. n. è.)", Lattara, 7, 155-179.

GARCÍA GANDÍA, J.R., 2001: "La necrópolis orientalizante de les Casetes", Revista de Arqueología, 249, 36-47.

GARRIDO, J.P., 1970: Excavaciones en la necrópolis de la Joya (Huelva). Primera y segunda campañas, E.A.E., 71, Madrid.

GARRIDO, J.P. y ORTA, E.M., 1978: Excavaciones en la necrópolis de la Joya (Huelva), II ( $3^{a}, 4^{a}$ y $5^{a}$ campañas, E.A.E., 96, Madrid

GONZÁLEZ PRATS, A., 2001: "Arquitectura Orientalizante en el Levante peninsular”, en D. Ruiz y S. Celestino (eds.): Arquitectura oriental y orientalizante en la Península Ibérica, C.S.I.C., Madrid, 173-192.

GONZÁLEZ PRATS, A., 2002: La necrópolis de cremación de Les Moreres (Crevillente, Alicante, España)(s. IX-VII AC), Alicante.

GONZÁLEZ PRATS, A. y RUIZ SEGURA, E., 1990-91: "Nuevos datos sobre urbanística y cultura material en el Hierro antiguo del Sudeste", Lucentum, IX-X, Alicante, 51-75.

GUALTIERI, M., 1996: "Residenze gentilizie di IV secolo a.C. a Roccagloriosa", Actas del Coloquio Ricerche sulla casa in Magna Grecia e in Sicilia, Universidad de Lecce, Archeologia e Historia, 5, Congedo Editore, 301-320.

HERNÁNDEZ PÉREZ, M. S., 2001: "La Edad del Bronce en Alicante",... Y acumularon tesoros. Mil años de historia en nuestras tierras, Alicante, 201-218.

HIESEL, G., 1990: Späthelladische Hausarchitektur, Mainz.

LANCEL, S., 1994: Cartago, Crítica, Barcelona.

LANCEL, S., MOREL, J.-P. y THUILLIER, J.-P., 1982: Byrsa II. Raports préliminaires sur les fouilles 1977-1978: niveaux et vestiges puniques, Roma.

LÓPEZ AMADOR, J. J., RUIZ GIL, J. A. y BUENO SERRANO, P., 1995: "Malacología arqueológica. Dos ejemplos del Bronce Final gaditano", Revista de Arqueología, $\mathrm{n}^{\circ}$ 174, 6-11.
LÓPEZ PRECIOSO, J. y SALA, F., 1999: "El poblado orientalizante de Los Almadenes (Hellín, Albacete) y la arquitectura protohistórica en las tierras interiores del Sureste", II Congreso de Arqueología Peninsular, t. III, Universidad de Alcalá de Henares, 229-238

LLOBREGAT, E., 1985: «Dos temples ibèrics a l'interior del poblat de l'illeta dels Banyets», Fonaments, 5, 103-112.

LLOBREGAT, E., 1988: "Un conjunto de templos ibéricos del siglo IV a.C. hallado en las excavaciones de la isla de Campello (Alicante) 2, Homenaje a Samuel de los Santos, 137-143, Albacete.

MAYET, F. y TAVARES DA SILVA, C., 2001: "Abul e a arquitectura orientalizante na costa portuguesa", en D. Ruiz y S. Celestino (eds.): Arquitectura oriental y orientalizante en la Península Ibérica, C.S.I.C., Madrid, 249-260.

MIMÓ, R., 1996: Fortalezas de barro en el sur de Marruecos, Compañía Literaria, Madrid.

MOLINER, M., 1987: Diccionario de uso del español, ed. Gredos, Madrid.

NEVETT, L., 1999: House and Society in the Ancient Greek World, Cambridge.

NORDSTRÖM, S., 1967: Excavaciones en el poblado de La Escuera (San Fulgencio, Alicante). T.V. del S.I.P., $\mathrm{n}^{\circ} 34$, Valencia.

PEÑA LIGERO, A., 2003: La necrópolis ibérica de El Molar (San Fulgencio, Alicante). Revisión de las excavaciones realizadas en 1928 y 1929, Fundación Municipal Jose María Soler, Villena.

PESANDO, F., 1987: Oikos e ktesis. La casa greca in età classica, Perugia.

PY, M., 1996: "Les maisons protohistoriques de Lattara", Urbanisme et architecture dans la ville antique de Lattes, Lattara, 9, Lattes, 141-258.

RAFEL, N., BLASCO, M. y SALES, J., 1994: "Un taller ibérico de tratamiento de lino en el Coll del Moro de Gandesa (Tarragona)", Trabajos de Prehistoria, 51, n 2, 121-136.

RAMOS FERNÁNDEZ, R., 1995: El templo ibérico de La Alcudia. La Dama de Elche, Ajuntament d'Elx.

RAPOPORT, A., 1969: House form and culture. Englewood Cliffs, N.J.

RAKOB, F., 1991: Karthago. Die deutschen Ausgrabungen in Karthago, Band I, Mainz am Rhein.

RUIZ, A., 1994: "Una reflexió teórica sobre l'urbanisme ibèric", Cota Zero, 10, 147-156.

RUIZ, A., 1996: "Desarrollo y consolidación de la ideología aristocrática entre los iberos del sur", Coloquio Internacional Iconografía ibérica, iconografía itálica: propuestas de interpretación y lectura, Varia 3, Universidad Autónoma de Madrid, 61-71.

RUIZ, A., 1998a: "Els ibers i el seu espai", en Els ibers. Prínceps d'occident, 1998, Catálogo de la exposición de Barcelona, 77-94.

RUIZ, A., 1998b: "Los príncipes iberos: procesos económicos y sociales",)", Actas del Congreso Internacional Los Iberos. Príncipes de Occidente, Fundación La Caixa, Barcelona, 289-300.

RUIZ, A. y SÁNCHEZ, A., 2003: "La cultura de los espacios y los animales entre los príncipes iberos del sur", en T. Tortosa y J.A. Santos (eds.): Arqueología e Iconografía. Indagar en las imágenes, Roma, 137-154.

RUIZ D. y CELESTINO, S. (eds.), 2001: Arquitectura oriental y orientalizante en la Península Ibérica, C.S.I.C., Madrid.

RUSSO, A., 1996: "Le abitazioni degli indigeni: problematiche generali", Actas del Coloquio Ricerche sulla casa in Magna Grecia e in Sicilia, Universidad de Lecce, Archeologia e Historia, 5, Congedo Editore, 67-88. 
SALA, F. y LÓPEZ PRECIOSO, J., 2000: "Los Almadenes (Hellín, Albacete), un poblado orientalizante en la desembocadura del río Mundo", IV Congreso Internacional de Estudios Fenicios y Púnicos, vol IV, Cádiz, 18851894.

SANMARTÍ, J. y BELARTE, C., 2001: "Urbanización y desarrollo de estructuras estatales en la costa de Cataluña (siglos VII-III a.C.)", Entre celtas e íberos. Las poblaciones protohistóricos de las Galias e Hispania, Bibliotheca Archaeologica Hispana, 8, Madrid, 161-174.

SANDERS, D., 1990: "Behavioral conventions and archaeology: methods for the analysis of ancient architecture", en S. Kent (ed.): Domestic architecture and the use of space. An interdisciplinary cross-cultural study, Cambridge, 4372

SANTOS VELASCO, J.A., 1998: "Los iberos: entre la consolidación de las elites y el surgimiento del Estado", Actas del
Congreso Internacional Los Iberos. Príncipes de Occidente, Fundación La Caixa, Barcelona, 399-404.

SOLER GARCÍA, J.M., 1972: "La leona ibérica del Zaricejo (Villena) y su contexto arqueológico", Revista del Instituto de Estudios Alicantinos, 7 de enero, 67-76.

SOLER GARCÍA, J.M., 1992: Excavaciones arqueológicas en el Cabezo Redondo (Villena, Alicante), Ayuntamiento de Villena-Instituto Juan Gil-Albert, Alicante.

TORELLI, M., 1996: Historia de los etruscos, Crítica, Barcelona (ed. orig. de 1981).

TORELLI, M., 2000: "Le regiae etruche e laziali tra orientalizzante e acaismo", en Catálogo de la exposición Principi etruschi tra Mediterráneo ed Europa, Bolonia, 67-78

VARELA BOTELLA, S., 2000: "Actuaciones arquitectónicas en dos monumentos de la antigüedad: Villajoyosa y Rojales", Scripta in honorem Enrique A. Llobregat Conesa, Alicante, 295-316. 